\title{
Scenario Simulation of The Geohazard Dynamic Process of Large-Scale Landslides: A Case Study of The Xiaomojiu Landslide Along The Jinsha River
}

Jianqi Zhuang ( $\sim$ jqzhuang@chd.edu.cn )

Chang'an University

Kecheng Jia

Chang'an University

Jiewei Zhan

Chang'an University

Yi Zhu

Chang'an University

Chenglong Zhang

Chang'an University

Jiaxu Kong

Chang'an University

Chenhui Du

Chang'an University

Shibao Wang

Chang'an University

Yanbo Cao

Chang'an University

Jianbing Peng

Chang'an University

\section{Research Article}

Keywords: Scenario simulation, Geohazards chains, Landslide failure, Flood simulation, Xiaomojiu landslide

Posted Date: November 16th, 2021

DOI: https://doi.org/10.21203/rs.3.rs-1074298/v1

License: (c) (1) This work is licensed under a Creative Commons Attribution 4.0 International License.

Read Full License 
Version of Record: A version of this preprint was published at Natural Hazards on February 14th, 2022. See the published version at https://doi.org/10.1007/s11069-022-05229-7. 
1 Scenario simulation of the geohazard dynamic process of large-scale landslides: a case study of the Xiaomojiu landslide along the Jinsha river

Jianqi Zhuang ${ }^{1} \cdot$ Kecheng Jia $^{1} \cdot$ Jiewei Zhan ${ }^{1} \cdot$ Yi Zhu $^{2} \cdot$ Chenglong Zhang ${ }^{1} \cdot$ Jiaxu Kong $^{1} \cdot$ Chenhui Du $^{1} \cdot$ Shibao

${ }^{1}$ College of Geological Engineering and Geomatics/Key Laboratory of Western China Mineral Resources and

Abstract

Large-scale landslides often cause severe damage due to their long run-out distances and having disaster chain effects. Scenario simulation has been adopted in the current work to analyze the Xiaomojiu landslide dynamic processes, such as sliding velocity, deposition characteristics, and flood outburst after a landslide-dam failure using Particle Flow Code (PFC-3D) which introduced the changeable friction coefficient and the HEC-RAS software. The landslide characteristics and topography data were obtained via field investigation, whereas high-resolution topographic data $(0.17 \mathrm{~m})$ was obtained using an Unmanned Aerial Vehicle (UAV). The results showed that: 1 . The landslide presents a scallop shape with a length of $1566 \mathrm{~m}$, a width ranging from 809 1124 m, and an area of $1.34 \times 10^{6} \mathrm{~m}^{2}$. The average thickness and volume of the sliding body is approximately 40 $\mathrm{m}, 5.1 \times 10^{7} \mathrm{~m}^{3}$. The InSAR deformation analysis showed that the Xiaomojiu landslide has a maximum annual displacement rate of $60 \mathrm{~mm} / \mathrm{y}$, and a maximum accumulation deformation of 180 mm since November 25, 2017. 2. From the landslide simulation results, the failure process of the Xiaomojiu landslide lasted for $65 \mathrm{~s}$ with a maximum velocity of $78.2 \mathrm{~m} / \mathrm{s}$. The deposited area is approximately $2023 \mathrm{~m}$ long, $900 \mathrm{~m}$ wide, with a maximum height of approximately $149 \mathrm{~m}$. 3. After the landslide blocks the Jinsha River, a landslide-dammed lake with an elevation of $2940 \mathrm{~m}$ and a storage capacity of $4.13 \times 109 \mathrm{~m}^{3}$ is formed. The maximum peak flow rate of the breach is 12051.7 $\mathrm{m}^{3} / \mathrm{s}, 43451.4 \mathrm{~m}^{3} / \mathrm{s}, 148635.6 \mathrm{~m}^{3} / \mathrm{s}$, and $304544.7 \mathrm{~m}^{3} / \mathrm{s}$ for the landslide-dammed failure degrees of 
$15 \%, 25 \%, 50 \%$, and $75 \%$, respectively. These results provide a scientific reference for the risk analysis and mitigation of the landslide.

Keywords Scenario simulation · Geohazards chains · Landslide failure · Flood simulation $\cdot$ Xiaomojiu landslide

\section{Introduction}

Large-scale landslides often cause severe damage due to their long run-out distances and having a significant disaster chain effect; thus, resulting in a large number of casualties, significant property loss, as well as damage to the ecological environment (Yin et al. 2016; Korup et al. 2019; Aslan et al. 2021). The complex geology and high-relief landform along the rivers indicate that a landslide has a large potential energy (Guo et al. 2020; Zhang et al. 2020; Gong et al. 2021). The failure and run-out process are complex and with the landslide materials traveling along the passway, resulting in a very high velocity with long run-out distances (Yang et al. 2014; Ge et al. 2019). Landslides that occur on both riverbanks produce landslide debris that can easily block the river and form a dammed lake. The water upstream of the dam body can then inundate residential areas and infrastructures. Moreover, the severity of dam failures and consequent flood bursts cause significant damage to downstream towns, transportation facilities, communication equipment, and the environment, thereby threatening the safety of human life (Liu et al. 2019; Fan et al. 2020a).

There are many catastrophic landslide occurrences globally, especially in the regions with landforms having higher elevation differences and frequent geohazards; thus, blocking rivers and forming landslide dams. For example, in 1933, a magnitude 7.5 earthquake occurred in Diexi, Maoxian County, Sichuan Province. This earthquake triggered a landslide that buried Diexi Town and blocked the Minjiang River, resulting in the formation of a dammed lake, which again broke and caused a massive flood killing more than 2500 people after 45 days (Zhao et al. 2019). In 2000, a landslide with debris spanning approximately $3 \times 10^{9} \mathrm{~m}^{3}$ occurred in Yigong, Tibet, blocking the Yigong River, and forming a 130m high landslide dam. The outburst flood from the breakage of this dam was $1.24 \times 10^{5} \mathrm{~m}^{3} / \mathrm{s}$ causing significant loss downstream (Delaney et al. 2015). In May 2008, another large-scale landslide occurred in Tangjiashan on the right bank of the Tongkou River triggered by the Wenchuan earthquake. The landslide blocked the Tongkou River and formed a 
landslide dam with a height that ranged from $82-124 \mathrm{~m}$ tall and having a storage capacity of nearly $3 \times 10^{9} \mathrm{~m}^{3}$. The landslide posed a significant threat to the lives of nearly a million people downstream (Cui et al. 2009). In October and November 2018, two landslides with volumes of $2.4 \times 10^{7} \mathrm{~m}^{3}$ and $8.50 \times 10^{6} \mathrm{~m}^{3}$ occurred in Baige Village along the Jiangda River. The landslides traveled a distance of $1,400 \mathrm{~m}$ and blocking the Jinsha River. This led to a rapid increase in the water content of the barrier lake $\left(3.85 \times 10^{8} \mathrm{~m}^{3}\right)$, causing devastating damage to coastal residents and infrastructure up to 1,000 kilometers downstream along the Jinsha River (Fan et al. 2020b; Zhang et al. 2020). Therefore, the formation and failure of landslides and landslide dams are sudden and extremely dangerous, and above all, it is extremely difficult to forecast and alleviate such catastrophes. Therefore, scenario simulation of the geohazards' dynamics processes of large-scale landslides and geohazards' chain of "landslide-blocking river-dam failure outburst flood" of the potential landslides is of utmost significance for the risk assessment and mitigation of the geohazard's (Zhang et al. 2019; Liu et al. 2019; Fan et al. 2020a).

With the advancement of computer simulation techniques and geohazard numerical simulations, they have the advantages of being less time-consuming, low cost, and the intuitive calculation results becoming the most effective method for studying the kinematic characteristics of landslides and the evolution of dam-breakage (Fan et al. 2017; Liu et al. 2015). Many scholars have studied large-scale landslide dynamics scenario simulations under different influencing factors (Bandara et al. 2015; Pastor et al. 2015; Yin et al. 2016; Gong et al. 2021) and flood evolution process simulations (Butt et al. 2013) based on numerical simulation methods in order to understand the mechanism of large-scale landslide failure and risk assessment. Numerical analysis has been widely adopted by several researchers in the past (1) To study the large-scale geohazard chain process based on post geohazards and comparing them with the geohazard characteristics in order to reproduce the geohazard chain process using a numerical simulation (He et al. 2015; Liu and He 2020). (2) Numerical simulation is also adopted to study the dynamic processes of the geohazards chain process under different triggering factors, such as the dynamic process of landslides caused by earthquakes (Sun et al. 2017; Wang et al. 2018; Sarma et al. 2020). Furthermore, groundwater affects the initiation process of a landslide as well as the landslide process caused by rainfall, loading, and unloading (Zhang et al. 2017; Zhang et al. 2019; Gong et al. 2020). (3) Numerical simulations were further used to carry out regional or single landslide scenario analysis, study the disaster loss 
and the damage zone caused by the geohazards, and provide a reference for risk analysis, assessment zoning, and disaster relief route selection (Loreto et al. 2017; Fan et al. 2020b; Mao et al. 2020). Scenario simulation of the dynamics of large-scale landslides and the detection of the longrunout of geohazard chains for a potential landslide is very important for risk assessment and the mitigation of the landslides, especially for site selection and planning of major projects (Liu and $\mathrm{He}$ 2020; Fan et al. 2020b). The current work aims to study a potential landslide, namely the XiaoMojiu landslide as the case study. The landslide characteristics and topography data were obtained through field investigations and UAV flights. The landslide model was built using high-resolution topographic data obtained from the UAV. The landslide failure process deposits, the landslide dam characteristics, and the dam-breakage flood evolution process were analyzed using PFC3D and HEC-RAS software.

\section{Area setting}

The Xiaomojiu landslide located in the east of the Qinghai-Tibet Plateau on the right bank of the Jinsha River in Jiangda County of the Tibet Autonomous Region (Fig. 1), is approximately $5 \mathrm{~km}$ upstream of the Baige landslide (E $\left.98^{\circ} 41^{\prime} 49^{\prime \prime}, \mathrm{N} 31^{\circ} 07^{\prime} 24^{\prime \prime}\right)$. Since the middle and late Pliocene era, due to strong uplifts of the Qinghai-Tibet Plateau, the height differences between both sides of the Jinsha River have become more prominent, and the valleys have been strongly cut (Chen et al. 2013), creating steep slopes. The landslide's top and toe elevations are $3655 \mathrm{~m}$ and $2900 \mathrm{~m}$, respectively; therefore, having a height difference of $755 \mathrm{~m}$. The toe of the landslide undergoes strong erosion by the Jinsha River and has a slope of approximately $30^{\circ}-35^{\circ}$.

Fig.1 The Xiaomojiu landslide setting area characters (base data from https://geocloud.cgs.gov.cn/\#/home)

The geological structure of the Xiaomojiu landslide is closely related to the tectonic evolution of the Qinghai-Tibet Plateau and is affected by the compression and collision of the Indian and the Asia-Europe plates. The eastern Qinghai-Tibet Plateau has strong tectonic deformation and uplift, making the eastern Qinghai-Tibet Plateau one of the most tectonically active areas. Typically, the faults and folds are found to be highly developed within this area (Cao et al. 2015). The concentrated development area of the unique geohazards formed by the action is primarily composed of 
metamorphic basic-ultrabasic rocks, metamorphic clastic rocks, and marble mixtures (Fig. 2). The south-north ductile shear mylonite belt and the strong schistosis belt are highly developed with a series of east-west squeezed imbricated inverses and fold structures (Zhang et al. 2016). The abovementioned geological background makes the Xiaomojiu landslide a typical high-steep valley structure consisting of a broken loose body structure that provides favorable topography and material for landslide failure.

Fig. 2 Geological characteristics near the Xiaomojiu landslide (base data from https://geocloud.cgs.gov.cn/\#/home)

The study area has a semi-humid climate within the plateau cold temperate zone having an average annual temperature of $7.5^{\circ} \mathrm{C}$ and an apparent vertical climate zoning. The average annual precipitation is approximately $650 \mathrm{~mm}$, and can reach a maximum of $1067.7 \mathrm{~mm}$. Furthermore, the precipitation has the characteristics of uneven temporal and spatial distribution primarily concentrated in June, July, August, and September. Additionally, the groundwater in the study area is primarily bedrock fissure and pore water. The main sources of the water are precipitation and melting ice and snow. The bedrock fissure water is primarily distributed within the bedrock fissures (Chen et al. 2013).

\section{Methods}

\subsection{Discrete element method}

The discrete element method (DEM) is an effective method for dynamic landslide analysis (Cundall and Strack 1979). PFC3D makes the following assumptions: (1) The particle unit is rigid; (2) All contacts between the particles occur only in small areas which can be regarded as point contacts; (3) The contact model is a flexible contact, that is at a contact point there exists a certain overlap; (4) According to the force-displacement law, the size of an overlap is related to the size of the contact force; therefore all of the overlaps are smaller than the particle diameter; (5) The contact between the particles can establish the bonding characteristics. The particle motion characteristics are calculated using Newton's second law of motion, whereas the law of force and displacement is used to update the position of the particles and describe the motion of the particles in the PFC3D discrete 
element method (Equations 1, 2, Itasca Consulting Group, Inc 2006):

$$
\begin{gathered}
F_{i}(t)+m g_{i}=\frac{m \Delta v_{i}}{\Delta t} \\
M_{i}=\frac{I \Delta \omega_{i}}{\Delta t}
\end{gathered}
$$

where $i=1,2,3$ are the three directions of $\mathrm{x}, \mathrm{y}, \mathrm{z} . F_{i}(t)$ is the unbalanced force of the particle at time $t, g$ is the acceleration of gravity, $\mathrm{m}$ is the particle mass, $M$ is the unbalanced moment, $\Delta t$ is the calculation time step, and $\omega$ is the angular acceleration. Then, the particle displacement $s_{i}$ and velocity $v_{i}$ are:

$$
\begin{aligned}
& s_{i}(t+\Delta t)=s_{i}(t)+v_{i}(t) \Delta t \\
& v_{i}(t+\Delta t)=v_{i}(t)+\frac{1}{m_{i}} F_{i}\left(s_{i}(t)\right) \Delta t
\end{aligned}
$$

\subsection{Determination of friction coefficient}

Many scholars set the friction coefficient as a fixed value while studying the dynamic process of large-scale landslides using numerical simulations, and they rarely consider changes in the friction coefficient (Han et al. 2010). However, numerous study results have shown that the friction coefficient of the rock during the sliding process is indefinite (Han et al. 2007; Han et al. 2010; Yao et al. 2013; Dong et al. 2017). The friction coefficient of a landslide varies due to the dynamic expansion, water hammer effects, sliding separation, or saturated liquefaction. Other effects, such as the air cushion layer, excessive pore water pressure, and rolling friction reduction, causes a reduction in the friction coefficient resulting in the high-speed and long-run outs of the landslide (Han et al. 2007; Han et al. 2010; Yao et al. 2013; Dong et al. 2017).

Han et al. (2010) proposed an empirical equation for the steady-state friction coefficient (Equation 5) including the velocity based on a rock high-speed friction test, and the friction coefficient during the sliding process.

$$
\mu_{s s}=\mu_{s s, \min }+\left(\mu_{s s, \max }-\mu_{s s, \min }\right) \exp \left[\ln (0.05)\left(\frac{v}{v_{c}}\right)\right]
$$

where $\mu_{s s}$ is the steady-state friction coefficient when the speed is $v, \mu_{s s, \max }$ is the steadystate friction coefficient at a small slip rate, $\mu_{s s, \min }$ is the steady-state friction coefficient when 
the speed progress to infinity, and $v_{c}$ is the critical speed. When the speed is $0, \mu_{s S}$ is equal to $\mu_{s s, \max }$; when the speed tends to be infinite, $\mu_{s s}$ is equals to $\mu_{s s, \min }$.

Based on the friction attenuation empirical formula proposed by Han et al. (2010), the present paper introduced a friction empirical formula showing how the friction coefficient changes with speed in the PFC3D model as well as simulating the landslides movement process. The flow chart is shown in Fig. 3.

Fig. 3 Flow chart of how the friction coefficient changes with speed

The simple model is shown in Figure 4 and was used to verify the accuracy of the program. The experimental materials of Han et al. (2010) were selected as the material for this verification simulation. The physical parameters are shown in the Table 1. The final simulation result is shown in Fig. 5, verifying the reliability and accuracy of the program.

Fig. 4 A simple model to verify the accuracy of the program

Table 1 Parameters of the model

Fig. 5 Plot showing the relationship between friction coefficient and speed

\subsection{Landslide simulation parameters}

In the discrete element method, the macroscopic properties of a particle depend on its mechanical contact properties. A uniaxial compression numerical test was used to obtain the macroscopic properties of the rock mass mechanics of the particle's combination. The size of the PFC3D simulation uniaxial compression test model was $100 \mathrm{~mm}$ in height and 50mm in radius (Fig. 6). The sample comprised of 7558 particles with a particle density of $2650 \mathrm{~kg} \cdot \mathrm{m}^{-3}$, the maximum and minimum particle size ratio was $4: 3$, the contact adopted a linear parallel bonding, the outside of the particles was restrained by the wall command, and the wall stiffness was $1 / 10$ of the particles stiffness. Loading was controlled by assigning speed to the upper and lower walls.

Fig. 6 The simulated triaxial test model 

bonding relationships. The properties of the spherical particles are determined by three parameters: $k_{n}, k_{s}$, and $\mu$. The bonding relationship was determined by $\overline{E_{c}}, \overline{k_{n}} / \overline{k_{s}}, \overline{\sigma_{b}}, \overline{\tau_{b}}$, and $\bar{\lambda}$. where, $k_{n}$ is the normal stiffness of the particle, $\overline{E_{c}}$ is the parallel bond modulus, $k_{n} / k_{s}$ and $\overline{k_{n}} / \overline{k_{s}}$ are the ratios of the normal stiffness and the tangential stiffness of the particle and the bond, $\overline{\sigma_{b}}$ is the parallel normal bond strength, $\overline{\tau_{b}}$ is the parallel tangential bond strength, and $\bar{\lambda}$ is the particle bond radius coefficient.

Table 2 Comparison of the uniaxial test between the numerical model and the laboratory experiment

The stress-strain curve was obtained through a uniaxial compression simulation test (Fig. 6). Table 2 shows the differences between the physical and mechanical properties obtained from the laboratory tests and numerical model parameters. The simulation test results fit very well with the laboratory tests. The uniaxial compression test parameters are considered to be the landslide simulation parameters (Table 3 ).

Table 3 Parameters of the triaxial test results

\subsection{Building the Simulation Model}

High-resolution three-dimensional terrain data $(0.17 \mathrm{~m})$ recorded by a UAV are used to build the landslide simulation model. Field investigation and remote sensing interpretation methods are also used to analyze the deformation characteristics of the slope; thus, combining the drilling data, the analyze the speed of different positions of the sliding body, four monitoring points were selected in the upper part (P1 P4), middle part (P5 P8), and the toe (P9 P12) of the sliding body in order to

Fig. 7 Simulation model of the Xiaomojiu landslide (base terrain from UAV obtained by authors) 
equation, is the most commonly used method for simulating outburst floods (Hydrologic Engineering Center 2012). Assuming that the fluid is incompressible, the mass conservation (continuity) equation is:

$$
\frac{\partial H}{\partial t}+\nabla \cdot h v+q=0
$$

Where, $t$ is time, $u$ and $v$ are the velocity components in the $x$ and $y$ directions, and $\mathrm{q}$ is the confluence; therefore, the momentum equation is:

$$
\frac{\partial V}{\partial t}+V \cdot \Delta V=-g \nabla H+v_{t} \nabla^{2} V-C_{f} V+f k \cdot V
$$

Where, $u$ and $v$ are the velocity components in the $x$ and $\mathrm{y}$ directions, $\mathrm{g}$ is the acceleration due to gravity, $v_{t}$ is the horizontal viscosity coefficient, $c_{f}$ is the bottom friction coefficient, $f_{v}$ and $f_{u}$ are the Coriolis parameters in the $x$ and $y$ directions, respectively.

\section{Characteristics of the Xiaomojiu landslide}

\subsection{Characteristics of Different zones}

As per the plan shown in Figure 8, the Xiaomojiu landslide is a scallop shape with a length of 1566 $\mathrm{m}$, a width of $809 \sim 1124 \mathrm{~m}$, and an area of $1.34 \times 10^{6} \mathrm{~m}^{2}$. The sliding direction of the landslide is NE46 $6^{\circ}$. The average thickness and volume of the sliding body are approximately $40 \mathrm{~m}$, and $5.1 \times 10^{7}$ $\mathrm{m}^{3}$, respectively. According to landslide characteristics and the drilling data, the Xiaomojiu landslide can be divided into two major areas: the landslide scar area (I) and the landslide deformation area (II). The landslide deformation area can be further divided into the upper sliding deformation zone (II1), the middle compression deformation zone (II 2), and the slope toe stress concentration zone (II 3) according to deformation characteristics (Fig. 8).

Fig. 8 The landslide deformation zone and side view of the landslide (base imagery and terrain from UAV obtained by authors)

The landslide scar area has a total length of approximately $2500 \mathrm{~m}$, an area of $3.3 \times 10^{5} \mathrm{~m}^{2}$, and an average height difference of about $105 \mathrm{~m}$. The bedrock of the scar area remains bare, and the vegetation coverage is minimal. After the landslide, the boundary of this area became very clear, and the rock mass was significantly broken. Several gullies were formed in this area, and the ridges 
in the northern area collapsed locally due to erosion, revealing that the first failure occurred a long time ago (Fig. 9).

Fig. 9 The landslide scar area (base imagery from UAV obtained by authors)

The upper sliding deformation zone ( II 1) is primarily distributed in the area with an elevation of $3326 \sim 3462 \mathrm{~m}$ and a slope of $22^{\circ}$. The longitudinal length and lateral width of this zone are $319 \mathrm{~m}$ and $280 \sim 680 \mathrm{~m}$, respectively. Additionally, the area and the volume of this zone are $1.7 \times 10^{5} \mathrm{~m}^{2}$ and $6.5 \times 10^{6} \mathrm{~m}^{3}$, respectively. The zone is comprised of six-level arc-shaped steps due to the deformation (Fig. 10). The steps are 91-257 $\mathrm{m}$ long, 22.4-64.0 $\mathrm{m}$ wide. The vertical dislocation of the steps ranges from 12.6 to $43.5 \mathrm{~m}$.

Fig. 10 The upper sliding deformation zone (base imagery from UAV obtained by authors)

The middle compression deformation zone (II 2) is primarily distributed in the area with an elevation of $3127-3326 \mathrm{~m}$ and a slope of $38^{\circ}$. The longitudinal length and lateral width of this zone are $385 \mathrm{~m}$ and $1010 \mathrm{~m}$, respectively. Furthermore, this zone has an area of $3.6 \times 10^{5} \mathrm{~m}^{2}$ and a volume of approximately $2.5 \times 10^{7} \mathrm{~m}^{3}$. Under the squeezing action of the upper sliding deformation zone (II1), the structure of the rock mass in this zone is significantly broken and weathered with the local convex landform. There are well-developed tension cracks in the southwestern edge of the deformation zone, providing a path for rainwater infiltration. Moreover, a secondary landslide has been found in this area whose length is $246 \mathrm{~m}$, width is approximately $310 \mathrm{~m}$ and, a height difference of $131 \mathrm{~m}$ (Fig. 11). The secondary landslide is a sign of shallow slippage due to road excavation.

Fig. 11 The middle compression deformation zone (base imagery from UAV obtained by authors)

The slope toe stress concentration zone (II 3) is a distributed area having an elevation of 2900$3127 \mathrm{~m}$ and a slope of $35^{\circ}$. This zone has a longitudinal length of $450 \mathrm{~m}$, and lateral width of 1150 $\mathrm{m}$. The area of this zone is $4.7 \times 10^{5} \mathrm{~m}^{2}$ and the volume is approximately $2.1 \times 10^{7} \mathrm{~m}^{3}$. Several local landslides occurred due to erosion by the Jinsha River. The maximum height of the landslide is approximately $89 \mathrm{~m}$ (Fig. 12). 
Fig. 12 The slope toe stress concentration zone (base imagery from UAV obtained by authors)

\subsection{Deformation characteristics}

76 SAR images were collected from the ALOS-2 satellite for the current study between 2017 and 2020. The SAR images were processed using terrain correction, time-space decoherence factors, and an atmospheric delay phase process (Zhao et al. 2016; Liu et al. 2021), thus obtaining the landslide's annual displacement rate since 2017 (Fig. 13a). Fig. 13b shows the displacement of the Xiaomojiu landslide since November 25, 2017. The maximum annual displacement rate of the landslide is $60 \mathrm{~mm} / \mathrm{y}$. Since 2017 , the deformation rate of the landslide has typically increased tending to aggravate the deformation. The maximum deformation reached a value of $180 \mathrm{~mm}$ over a 3 year period. During this period, the slope deformation was primarily concentrated in the middle and upper parts of the slope, indicating that the landslide is induced by gravity or fault activity and has an apparent nature of instability.

Fig. 13 The deformation characteristics of the Xiaomojiu landslide using InSAR (base imagery from UAV obtained by authors)

\section{Results}

\subsection{Dynamic characteristics}

Fig. 14 shows the dynamic process of the Xiaomojiu landslide, whereas Figure 15 shows the friction coefficient distribution of the landslide at different times with the changeable friction coefficient. The landslide motion lasted for about $65 \mathrm{~s}$ and comprised of three stages: initiation phase (Fig. 14ab, Fig. 14a-b), acceleration phase (Fig. 14c-d, Fig. 14c-d), and deceleration accumulation phase (Fig. 14e-f, Fig. 15e-f). At the initiation phase, the sliding body began to slide slowly along the bedrock. The landslide showed an overall instability failure after $4 \mathrm{~s}$ with a friction coefficient of $0.25-0.35$. At $12 \mathrm{~s}-26 \mathrm{~s}$, the sliding body accelerated sliding along the bedrock, and the potential energy of gravity converted into kinetic energy. At this time, the sliding body started to block the river. The landslide toe particles rushed into the channel first and reached the peak velocity. The friction coefficient attenuated to $0.10-0.15$. During $26-64 \mathrm{~s}$, the landslide was in the deceleration 
accumulation stage. The sliding body passed through the river channel with the front-edge particles blocked by the mountain on the opposite bank. The energy consumed due to collision, tumbling, and friction started to decelerate. The sliding body accumulated on the opposite side of the mountain slope and on both sides of the rivers. The speed of the upper particles of the landslide decreased rapidly, and the coefficient of friction increased rapidly until it reached a maximum value of 0.50 . At $64 \mathrm{~s}$, most of the particles stopped moving.

Fig. 14 The dynamic process of the Xiaomojiu landslide (a.t=4s b.t=12s c.t=26s d.t=39s e.t=53s f.t=64s, base terrain from UAV obtained by authors)

Fig. 15 The changing characteristics of the friction coefficient during dynamic process $(a . t=4 \mathrm{~s} b . t=12 \mathrm{~s}$ c.t $=26 \mathrm{~s}$ d.t $=39 \mathrm{~s}$ e. $\mathrm{t}=53 \mathrm{~s}$ f. $\mathrm{t}=64 \mathrm{~s}$, base terrain from UAV obtained by authors)

Fig. 16 shows the plot of the speed vs. average speed of the monitoring points in different parts of the landslide. Comparing the average velocities of different parts of the sliding body, it was found that the particles of the upper-part (P1-P4) of the landslide had three sharp rises and drops in velocity before reaching the peak velocity. The velocities of the toe (P9-P12), middle- (P5-P8), and upper-part particles (P1-P4) of the landslide reached peak values in $26 \mathrm{~s}, 34 \mathrm{~s}$, and $42 \mathrm{~s}$, respectively. Due to the significant height difference in the movement path of the upper-part particles (P1-P4) of the sliding body, the peak velocity was significantly greater than the peak velocities of the toe (P9P12) and middle-part (P5-P8) particles. For example, the peak velocity of the P1-4 monitoring points was $61.4 \mathrm{~m} / \mathrm{s}$, the peak velocity of the P5-8 monitoring points was $70.1 \mathrm{~m} / \mathrm{s}$, and the peak velocity of the P9-12 monitoring points was $78.2 \mathrm{~m} / \mathrm{s}$.

Fig. 16 The point velocity of the Xiaomojiu landslide

\subsection{Characteristics of the Deposited Zone}

Fig. 17 shows the characteristics of the deposited zone with a changing friction coefficient. From the perspective of the plane distribution, the landslide traveled a distance of approximately $780 \mathrm{~m}$, and the total area of the deposits was approximately $7.9 \times 10^{5} \mathrm{~m}^{2}$. The deposited area presented an uneven oval shape, thin on both sides and thick in the middle. The maximum thickness was $149 \mathrm{~m}$. 
Fig. 17 The deposition characteristics of the Xiaomojiu landslide (base imagery and terrain from UAV obtained by authors)

According to the simulation results, the deposited area blocked the Jinsha River to form a huge landslide dam. The landslide dam was spindle-shaped with a maximum thickness of $149 \mathrm{~m}$. The elevations of the left and right banks were $2940 \mathrm{~m}$ and $3000 \mathrm{~m}$, respectively. A dam break model was established based on the above profile.

\subsection{Outburst flood simulation}

According to the landslide simulation results, the height of the landslide dam blocking the Jinsha

River was between 2940 and $3000 \mathrm{~m}$. The dam height that was considered the final submerged elevation was $2940 \mathrm{~m}$, and the maximum storage capacity was $4.13 \times 10^{9} \mathrm{~m}^{3}$. Considering the average annual flow in the upper reaches of the Jinsha River to be $957.3 \mathrm{~m}^{3} / \mathrm{s}$, the dammed lake was $75 \%$ dam failure.

Fig. 18 shows the flow discharge process of the different scenarios of landslide dam failure. year return flow of the Jinsha River at the landslide site.

Fig. 18 Flood discharge processes for different dam failures at different sites (a, 15\% dam failure; b, 25\% dam failure; c, 50\% dam failure; and d, 75\% dam failure) (Z1, 69km), the Lawa Hydropower Station (Z2, $140 \mathrm{~km})$, the Batang Hydropower Station (Z3, 163 $\mathrm{km})$, and the Zhubalong Jinsha Bridge $(\mathrm{Z} 4,180 \mathrm{~km})$ were selected for flood analysis. The flood discharge process of each section for different scenarios of landslide dam failure is shown in Figure 
18. It can be seen from the figure that the flood discharge first increased rapidly, then reached a peak flow value, and finally decreased slowly. The flood discharge curves for different scenarios of the landslide dam failure have similar characteristics: the peak discharge gradually decreases along the way, the discharge process spreads downward in a single peak form, and the farther the distance from the dam, the wider the peak shape. As shown in Table 4, each section's peak flood and arrival time are related to the different scenarios of the landslide dam failure. As the degree of dam failure increases, the flood peak discharge of each section also increases, and the shorter the time it takes the flood to reach each section. For $75 \%$ dam failure, the peak flow discharge of each section was the largest and the arrival time was the fastest. Conversely, for $15 \%$ dam failure, the peak flow discharge of each section was the smallest, and the time to reach each section was the slowest.

Table 4 Flood discharge and arrival time at different sections and for different dam failures

\section{Discussions}

Numerical simulation of geohazard chains is considered the most effective method to reveal the dynamics of landslides and the scenario analysis of potential landslides (Mao et al. 2020; Liu and He 2020). In this area, most of the published articles focused mainly on the simulation analysis of the dynamic process of post landslides as well as studying the initiation mechanism and characteristics of post landslides (Yang et al. 2014; Delaney et al. 2015; Yin et al. 2016; Ge et al. 2019; Guo et al. 2020). In contrast, only a handful of studies concerning the dynamic process and scenario analysis of potential landslides can be found. Moreover, the friction coefficient is often treated as a constant having a fixed value during the process of numerical simulation, which is not true (Han et al. 2007; Yao et al. 2013; Dong et al. 2013). Based on the existing research and the friction attenuation characters obtained from the high-speed rock friction test, the current study has proposed that the friction coefficient is related to the landslide's speed, and therefore, is included in the landslide simulation. Furthermore, the simulation of the decrease in the friction coefficient and the aggravation of the high-speed motion phenomenon in the landslide process.

Fig. 19 shows the characteristics of the deposited zone which included both the friction attenuation empirical formula (model 1) and the fixed friction coefficient (model 2). Concerning 
plane distribution, the lateral deposited length of model 1 was larger than that of model 2. However, due to the obstruction of the mountain on the opposite bank, the difference between the horizontal and vertical accumulation lengths of the two models was not notable. The edges of the accumulated bodies along the two sides of the river channel appeared to be discontinuously distributed. In contrast, the distribution of model 1 was uniform, indicating that the model combined with the changeable friction coefficient and depicted high mobility and continuity of the landslide.

Fig. 19 The different deposition characteristics of the Xiaomojiu landslide with changeable and fixed friction coefficients revealed a distinct speed difference in the landslide during the movement process for the varied and fixed friction coefficients. The maximum speeds of the landslide with changeable friction coefficient were $55 \mathrm{~m} / \mathrm{s}, 63 \mathrm{~m} / \mathrm{s}$, and $65 \mathrm{~m} / \mathrm{s}$ of the toe, middle, and upper parts of the landslide, respectively, which were higher than those with fixed friction coefficient $(31 \mathrm{~m} / \mathrm{s}, 33 \mathrm{~m} / \mathrm{s}$, and $42 \mathrm{~m} / \mathrm{s}$, Fig. 20). The speed of the landslide after the introduction of the varied friction coefficient was much dynamic characteristics.

Fig. 20 Average velocities of different parts of the Xiaomojiu landslide with changeable and fixed friction coefficients

\section{Conclusions}

In summary, the current study has established a landslide mode using high-precision threedimensional topographic data $(0.17 \mathrm{~m})$ obtained by UAV. Through scenario simulation, the specific dynamic processes of the Xiaomojiu landslide were studied. More specifically, sliding velocity, deposition characteristics, and flood outbursts after landslide-dam failure were analyzed using PFC3D introducing the changeable friction coefficient and the HEC-RAS software. The primary conclusions derived from this work are as follows.

(1) According to the characteristics of the Xiaomojiu landslide, the landslide was divided into 
two areas: the landslide source area and the landslide deformation area. The landslide deformation area was further divided into the upper slumping deformation zone, middle compression deformation zone, and the slope toe stress concentration zone. The Xiaomojiu landslide has a maximum annual displacement rate of $60 \mathrm{~mm} / \mathrm{y}$ and the maximum accumulate deformation has been $180 \mathrm{~mm}$ since November 25, 2017, according to the InSAR deformation analysis.

(2) The failure process of the Xiaomojiu landslide lasted for approximately $65 \mathrm{~s}$, and the maximum velocity was $78.2 \mathrm{~m} / \mathrm{s}$. According to the simulation, the deposited area was approximately $2023 \mathrm{~m}$ long, and $900 \mathrm{~m}$ wide, with a maximum depth of approximately $149 \mathrm{~m}$.

(3) The landslide-dammed lake formed by the Xiaomojiu landslide failure had a storage capacity of $4.13 \times 10^{9} \mathrm{~m}^{3}$, and the maximum peak flow discharge of the breach was $12051.7 \mathrm{~m}^{3} / \mathrm{s}$, $43451.4 \mathrm{~m}^{3} / \mathrm{s}, 148635.6 \mathrm{~m}^{3} / \mathrm{s}$, and $304544.7 \mathrm{~m}^{3} / \mathrm{s}$ for landslide-dam failure degrees of $15,25,50$, and $75 \%$, respectively. The flood peak discharge and arrival time of each downstream section was at $69 \mathrm{~km}, 140 \mathrm{~km}, 163 \mathrm{~km}$, and $180 \mathrm{~km}$ downstream distance from the landslide dam.

Authors' contributions Jianqi Zhuang, Kecheng Jiua, and Jiewei Zzhan designed the analysis, developed the model code and performed analysis. Yi Zu, Chenglong Zhang, Jiaxu Kong, Chendui Du and Shibao Wang curated data and field investigations. Jianqi Zhuang, Jianbing Peng and Yanbo Cao prepared the manuscript with contributions from all co-authors.

Funding This study was financially supported by the National Natural Science Foundation of China (41941019, 41922054), National Key Research and Development Plan Project (No. 2020YFC1512000) and Fundamental Research Funds for the Central Universities, CHD 300102260302. The authors thank AiMi Academic Services (www.aimieditor.com) for the English language editing and review services.

The funders had no role in the design of the study and collection, analysis and interpretation of data and in writing or approving the manuscript.

Data availability The data that support the findings of this study are available from the corresponding author, Jianqi Zhuang, upon reasonable request. 
450 Conflict of interest The authors have no conflicts of interest to declare that are relevant to the content 451 of this article.

452 Human and animal rights This research does not involve human or animal participants.

The authors declare that they have no conflict of interest.

\section{Reference}

Aslan G, De Michele M, Raucoules D, Bernardie S, Cakir Z (2021) Transient motion of the largest landslide on earth, modulated by hydrological forces. Sci Rep 11:10407.

Bandara S, Soga K (2015) Coupling of Soil Deformation and Pore Fluid Flow Using Material Point Method. Computers \&Geotechnics 63:199-214.

Butt MJ, Umar M, Qamar R (2013) Landslide dam and subsequent dam-break flood estimation using HEC-RAS model in Northern Pakistan. Natural Hazards 65(1):241-254.

Cao W, Yan DP, Qiu L, Zhang YX, Qiu JW (2015) Structural style and metamorphic conditions of the Jinshajiang metamorphic belt: Nature of the Paleo-Jinshajiang orogenic belt in the eastern Tibetan Plateau. Journal of Asian Earth Sciences 113(2):748-765.

Chen J, Dai FC, Lv TY, Cui ZJ (2013) Holocene landslide-dammed lake deposits in the Upper Jinsha River, SE Tibetan Plateau and their ages Quaternary International 298:107-113.

Cui P, Zhu YY, Han YS, Chen XQ, Zhuang JQ (2009) The 12 May Wenchuan earthquake-induced landslide lakes: distribution and preliminary risk evaluation. Landslides 6(3):209-223.

Cundall P A, Strack ODL (1979) A discrete numerical model for granular assemblies. Geotechnique 29(1):47-65.

Delaney KB, Evans SG (2016) The 2000 Yigong landslide (Tibetan Plateau), rockslide-dammed lake and outburst flood: Review, remote sensing analysis, and process modelling. Geomorphology 246:377-390.

Dong JJ, Yang CM, Yu WL, Lee CT, Miyamoto Y, Shimamoto T (2013) Velocity-displacement dependent friction coefficient and the kinematics of giant landslide. Earthquake-induced landslides pp:397-403. State of the art. Earth-Science Reviews 203:10316.

Fan X, Xu Q, Scaringi G, Dai L, Havenith HB (2017) Failure mechanism and kinematics of the deadly June 24th 

Prediction of a multi-hazard chain by an integrated numerical simulation approach: the Baige landslide, Jinsha River, China. Landslides 17: 147-164.

Ge YF, Tang HM, Eldin M, Chen HZ, Zhong P, Zhang L, Fang K (2019) Deposit characteristics of the Jiweishan rapid long-runout landslide based on field investigation and numerical modeling. Bulletin of Engineering Geology and the Environment 78(6):4383-4396.

Gong W, Juang CH, Wasowski J (2021) Geohazards and human settlements: Lessons learned from multiple

Gong W, Tang H, Juang CH, Wang L (2020) Optimization design of stabilizing piles in slopes considering spatial

Guo CB, Montgomery DR, Zhang YS, Zhong N, Fan C, Wu RA, Yang ZH, Ding YY, Jin JJ, Yan YQ (2020) Evidence

Han R, Hirose T, Shimamoto T (2010) Strong velocity weakening and powder lubrication of simulated carbonate faults at seismic slip rates. Journal of Geophysical Research: Solid Earth 115:B3.

Han R, Shimamoto T, Hirose T, Ree JH, Ando JI (2007) Ultralow friction of carbonate faults caused by thermal decomposition. Science 316(5826):878-881.

He SM, Li W, Wang J (2015) Dynamic simulation of landslide based on thermo-poro-elastic approach. Computers \& Geosciences 85:81-90.

Hydrologic Engineering Center (2012) HEC-RAS User's Manual 4.1. Davis CA: US Army Corps of Engineer. Itasca Consulting Group Inc (2006) PFC3D user's manual. Minneapolis, USA: Itasca Consulting Group, Inc..

Korup O, Seidemann J, Mohr CH (2019) Increased landslide activity on forested hillslopes following two recent volcanic eruptions in Chile. Nat Geosci 12:284-289.

Liu WM, Carling PA, Hu KH, Wang H, Zhou Z, Zhou LQ, Liu DZ, Lai ZP, Zhang XB (2019) Outburst floods in China: A review. Earth-Science Reviews 197:102895.

Liu W, He SM, Li XP, Xu Q (2015) Two-dimensional landslide dynamic simulation based on a velocity-weakening friction law. Landslides 13(5):1-9.

Liu W, Ju NP, Zhang Z, Chen Z, He SM (2020) Simulating the process of the Jinshajiang Landslide-caused disaster chain in October 2018. Bulletin of Engineering Geology and the Environment 79(1):2189-2199. 

China. Engineering Geology 284:106033. geohazard assessment. Engineering geology 224:1-14.

Mao J, Liu XN, Zhang C, Jia GX, Zhao LH (2020) Runout Prediction and Deposit Characteristics Investigation by the Distance Potential-Based Discrete Element Method: The 2018 Baige Landslides, Jinsha River, China. Landslides 18(1):235-249. Archives of Computational Methods in Engineering 22(1):1-38.

Sarma CP, Dey A, Krishna AM (2020) Influence of digital elevation models on the simulation of rainfall-induced landslides in the hillslopes of Guwahati, India. Engineering Geology 268:105523.

Sun XP, He SM, Gao CF, Liu BH (2017) Discrete Element Numerical Analysis of Niujuangou landslide. Journal of Lanzhou University(Natural Sciences) 53(1):48-53.

Wang Y, Zhuang JQ, LiW, Zhao Y, Jia YJ (2018) Discrete Element Simulation of Instability and Movement Process of Loess Slope Under Seismic Load. Journal of Engineering Geology 26(5):1139-1154.

Yang CM, Yu WL, Dong JJ, Kuo CY, Shimamoto T, Lee CT, Togo T, Miyamoto, T (2014) Initiation, movement, and run-out of the giant Tsaoling landslide-What can we learn from a simple rigid block model and a velocitydisplacement dependent friction law. Engineering Geology 182:158-181.

Yao L, Ma S, Shimamoto T, Togo T (2013) Structures and high-velocity frictional properties of the Pingxi fault zone in the Longmenshan fault system, Sichuan, China, activated during the 2008 Wenchuan earthquake. Tectonophysics 599:135-156.

Yin YP, Xing AG, Wang GH, Feng Z, Li B, Jiang Y (2016) Experimental and numerical investigations of a catastrophic long-runout landslide in Zhenxiong, Yunnan, Southwestern China. Landslides 14(2):1-11.

Zhang DQ, Jiang XY, Zou NN, Luo BJ (2019) Numerical Analysis of Colluvial Landslide Stability under the Effect of Rainfall Infiltration:Taking Darong Landslide of Guizhou Province for an Example. Science Technology and Engineering 19(26):338-344.

Zhang H, Oskin ME, Liu Z, Zhang PZ, Reiners PW, Xiao P (2016) Pulsed exhumation of interior eastern Tibet: Implications for relief generation mechanisms and the origin of high-elevation planation surfaces. Earth and 
Zhang M, Wu LZ, Zhang JC, Li LP (2019) The 2009 Jiweishan rock avalanche,Wulong,China: deposit characteristics and implications for its fragmentation. Landslides 16(5):893-906.

540 Zhang SL, Yin YP, Hu XW, Wang WP, Zhang N, Zhu SN, Wang LQ (2020) Dynamics and emplacement mechanisms

541 of the successive Baige landslides on the Upper Reaches of the Jinsha River, China. Engineering Geology $542 \quad 278: 105819$.

Zhang XR, Yin KL, Xia H, Li Y (2017) Influence of Permeability Coefficient and Reservoir Water Level Fluctuation on Xiaping Landslide Stability. Journal of Engineering Geology 25(2):488-495.

Zhao C, Kang Y, Qin Z, Wu Z, Li B (2016) Landslide detection and monitoring with InSAR technique over upper reaches of Jinsha River, China. In, 2016 IEEE International Geoscience and Remote Sensing Symposium (IGARSS) pp:2881-2884,

548 Zhao S, Chigira M, Wu X (2019) Gigantic rockslides induced by fluvial incision in the diexi area along the eastern margin of the Tibetan Plateau. Geomorphology 338(1):27-42. 
Tables:

Table 1 Parameters of the model

\begin{tabular}{ccccc}
\hline Parameters & Density $\left(\mathrm{kg} / \mathrm{m}^{3}\right)$ & $\begin{array}{c}\text { Young's modulus } \\
(\mathrm{GPa})\end{array}$ & $\begin{array}{c}\text { Uniaxial compressive strength } \\
(\mathrm{MPa})\end{array}$ & $\begin{array}{c}\text { Poisson's } \\
\text { ratio }\end{array}$ \\
\hline value & 2500 & 30 & 75 & 0.25 \\
\hline
\end{tabular}

3

4

5 Table 2 Comparison of the uniaxial test between the numerical model and laboratory experiment

\begin{tabular}{|c|c|c|c|c|c|}
\hline & & $\begin{array}{l}\text { Density } \\
\left(\mathrm{kg} / \mathrm{m}^{3}\right)\end{array}$ & Young's modulus（GPa） & $\begin{array}{l}\text { Uniaxial compressive } \\
\text { strength }(\mathrm{MPa})\end{array}$ & Poisson's rati \\
\hline & Laboratory test & 2650 & 19 & 64 & 0.27 \\
\hline & Simulation test & 2650 & 18 & 64 & 0.26 \\
\hline \multicolumn{6}{|l|}{6} \\
\hline \multicolumn{6}{|l|}{7} \\
\hline \multirow[t]{10}{*}{8} & \multicolumn{5}{|c|}{ Table 3 Parameters of the triaxial test results } \\
\hline & \multicolumn{3}{|c|}{ Simulation parameters } & Value & \\
\hline & \multicolumn{3}{|c|}{$\boldsymbol{k}_{\boldsymbol{n}} / \mathrm{MPa}$} & 6.7 & \\
\hline & \multicolumn{3}{|c|}{$\boldsymbol{k}_{n} / \boldsymbol{k}_{\boldsymbol{s}}$} & 1 & \\
\hline & \multicolumn{3}{|c|}{$\mu$} & 0.3 & \\
\hline & \multicolumn{3}{|c|}{$\bar{\lambda}$} & 1 & \\
\hline & \multicolumn{3}{|c|}{$\overline{\boldsymbol{E}_{\boldsymbol{c}}} / \mathrm{GPa}$} & 3.1 & \\
\hline & \multicolumn{3}{|c|}{$\overline{\boldsymbol{k}_{n}} / \overline{\boldsymbol{k}_{\boldsymbol{s}}}$} & 1.2 & \\
\hline & \multicolumn{3}{|c|}{$\overline{\boldsymbol{\sigma}_{\boldsymbol{b}}} / \mathrm{MPa}$} & 71 & \\
\hline & \multicolumn{3}{|c|}{$\overline{\boldsymbol{\tau}_{\boldsymbol{b}}} / \mathrm{MPa}$} & 71 & \\
\hline
\end{tabular}

9

10 Table 4 Flood discharge and arrival time at different sections and for different dam failures

\begin{tabular}{cccc}
\hline & $\begin{array}{c}\text { distance from dam } \\
(\mathrm{km})\end{array}$ & $\begin{array}{c}\text { Peak flood discharge } \\
\left(\mathrm{m}^{3} / \mathrm{s}\right)\end{array}$ & Arrival time $(\mathrm{h})$ \\
\hline $15 \%$ & & & \\
Dam site & 0 & 12051.7 & 0 \\
Z1 & 69 & 9447.3 & 2.5 \\
Z2 & 140 & 8747.9 & 5.8 \\
Z3 & 163 & 7901.5 & 8.0 \\
Z4 & 180 & 7644.6 & 10.0 \\
$25 \%$ Dam site & 0 & & 0 \\
Z1 & 69 & 43451.4 & 2.3 \\
Z2 & 140 & 34965.2 & 5.3 \\
Z3 & 163 & 30488.1 & 7.6 \\
Z4 & 180 & 28993.0 & 9.6 \\
$50 \% \quad$ & 27898.7 & 0 \\
Dam site & 0 & & 2.1 \\
Z1 & 69 & 148635.6 &
\end{tabular}




\begin{tabular}{cccc} 
Z2 & 140 & 108373.8 & 5.0 \\
Z3 & 163 & 103557.7 & 7.3 \\
Z4 & 180 & 99338.2 & 9.3 \\
$75 \%$ Dam site & 0 & 304544.7 & \\
Z1 & 69 & 228908.2 & 0 \\
Z2 & 140 & 222692.0 & 1.9 \\
Z3 & 163 & 210628.3 & 4.9 \\
Z4 & 180 & 204134.3 & 7.2 \\
\hline
\end{tabular}

11 
Figures:

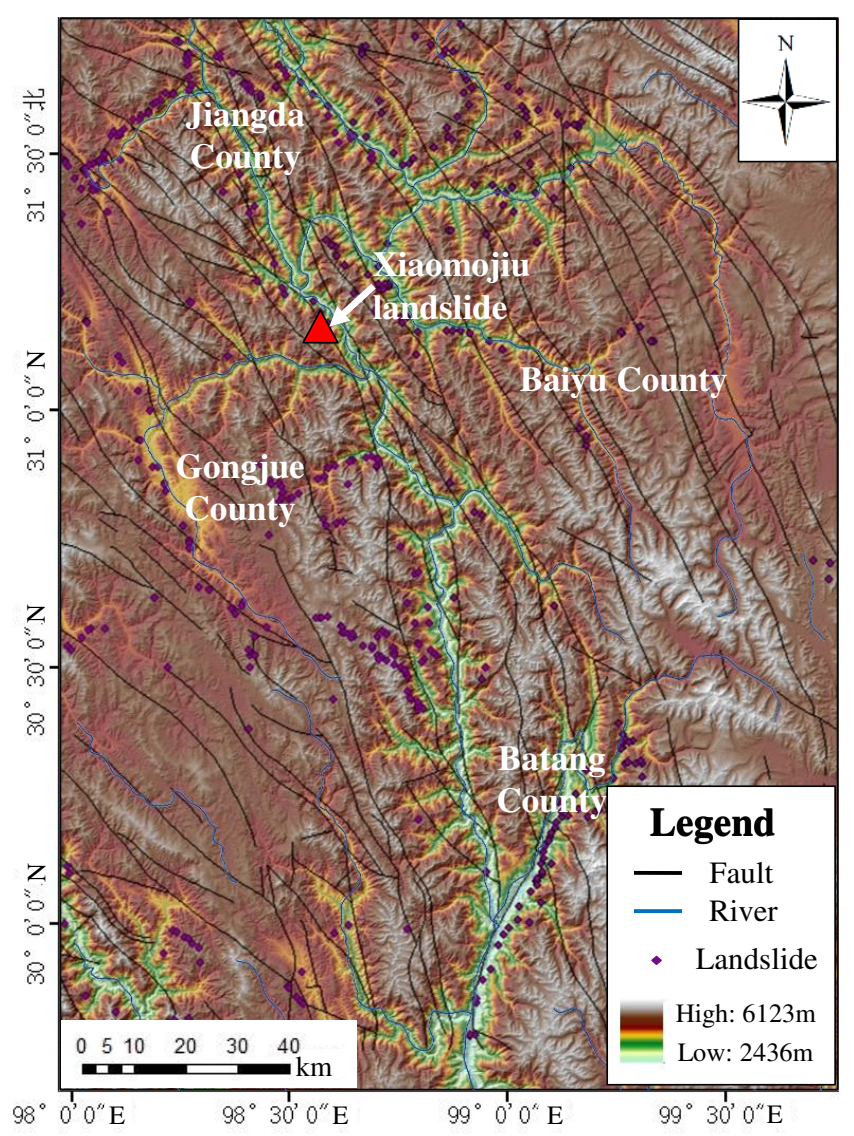

2

Fig. 1 The Xiaomojiu landslide setting area characters (base data from https://geocloud.cgs.gov.cn/\#/home) 


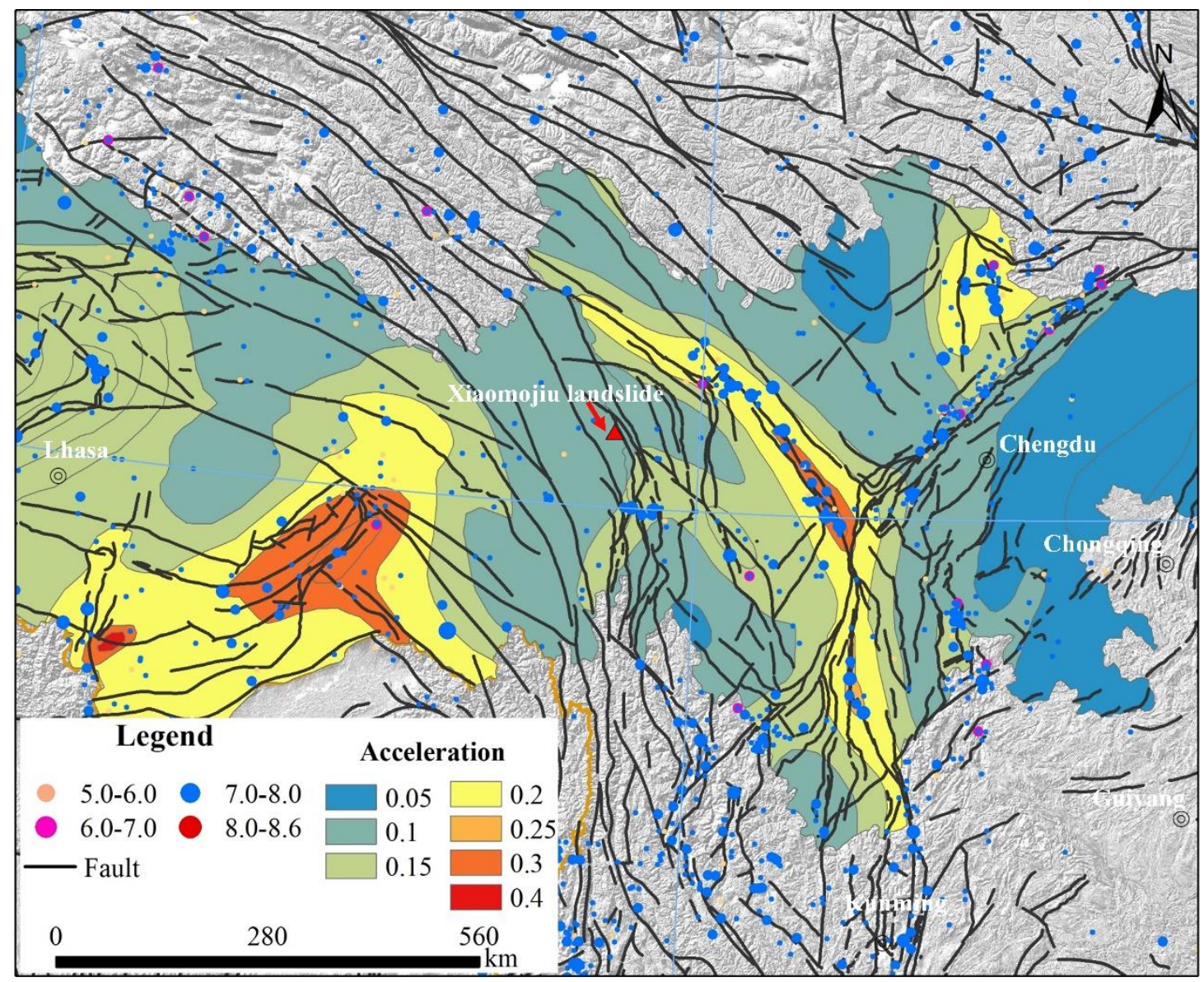

Fig. 2 Geological characteristics near the Xiaomojiu landslide (base data from https://geocloud.cgs.gov.cn/\#/home) 


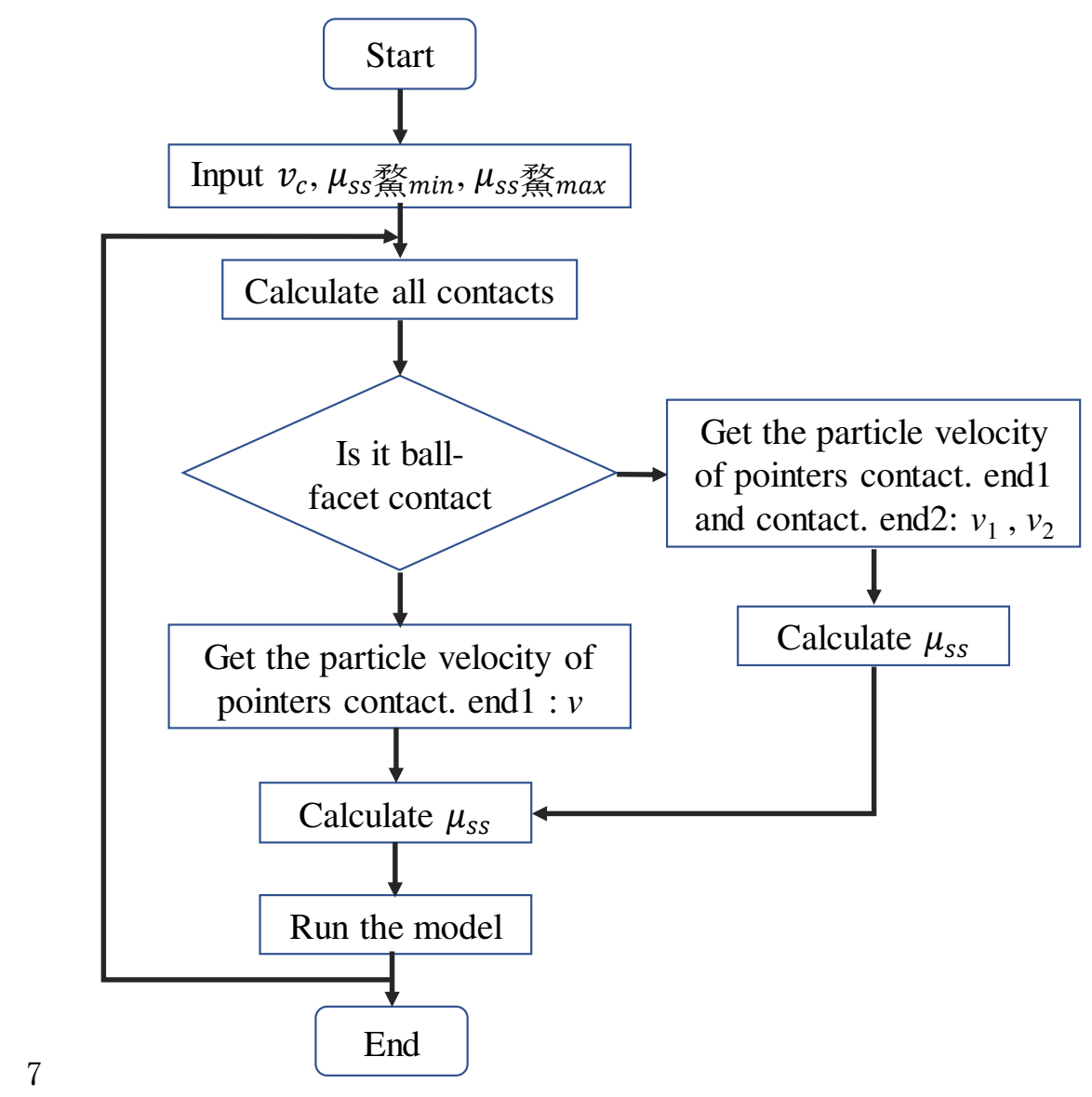

8 Fig. 3 Flow chart of the friction coefficient changes with speed

9

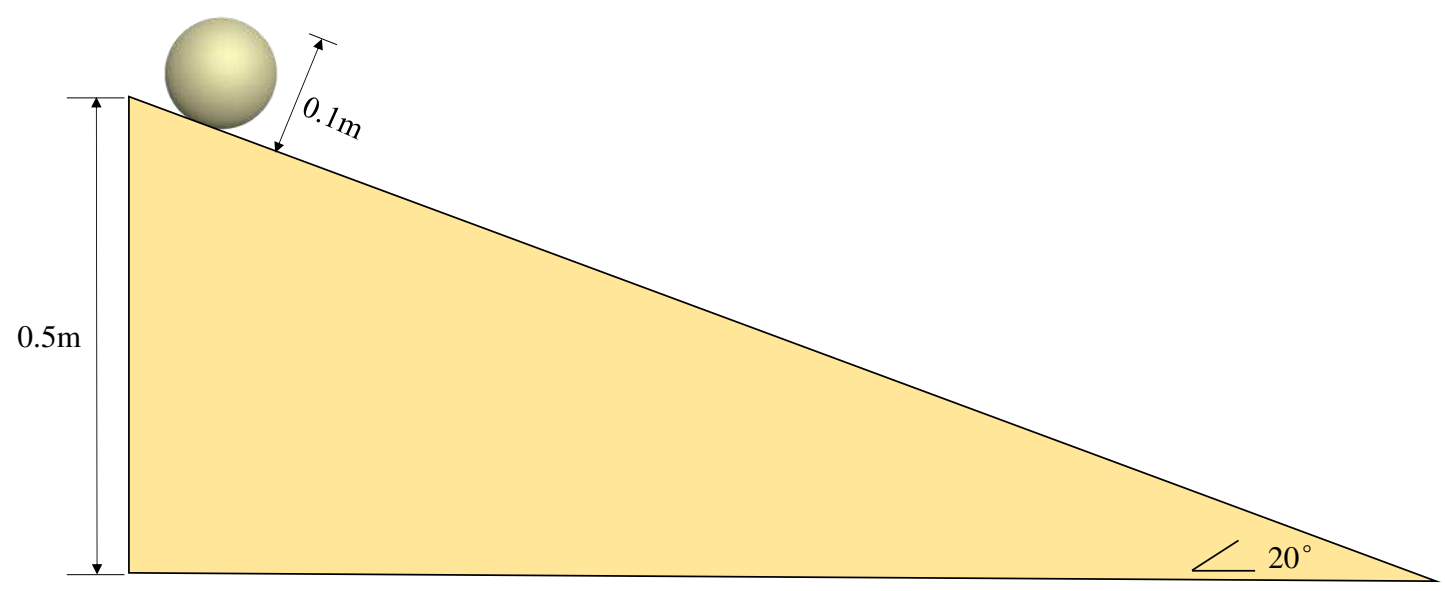

Fig. 4 A simple model to verify the accuracy of the program 


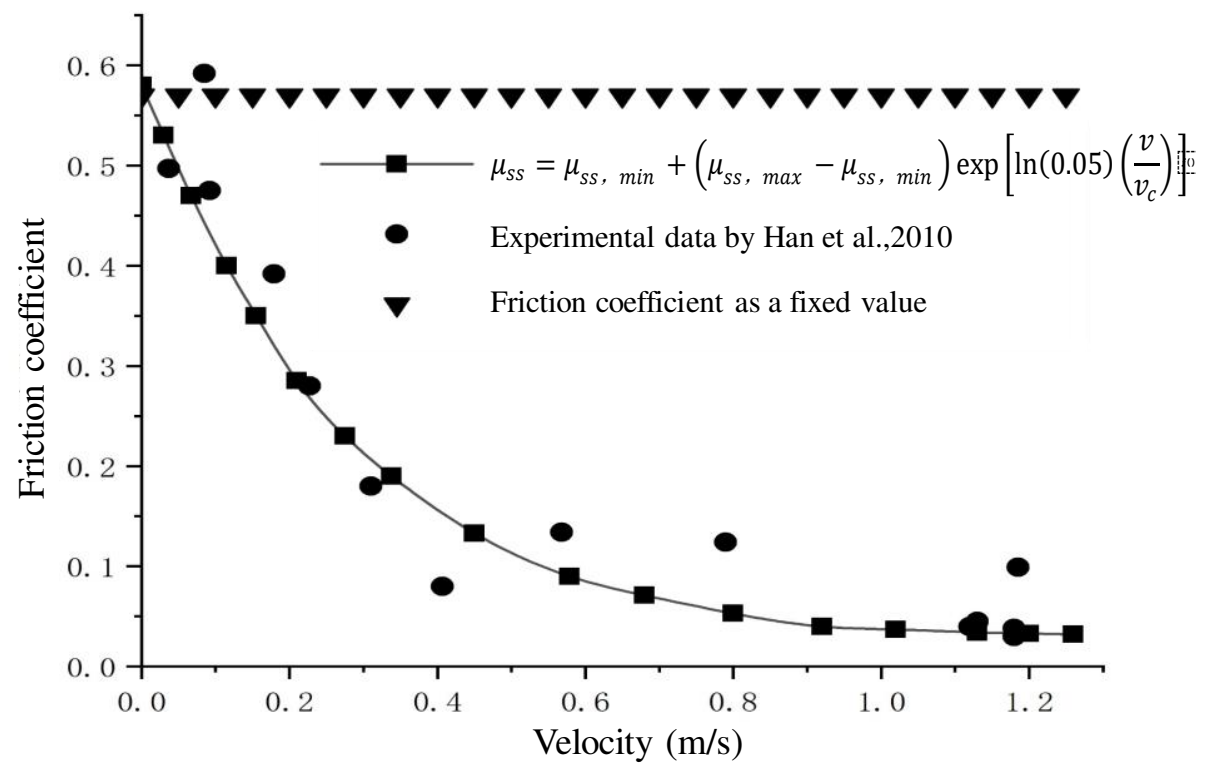

Fig. 5 Plot showing the relationship between friction coefficient and speed

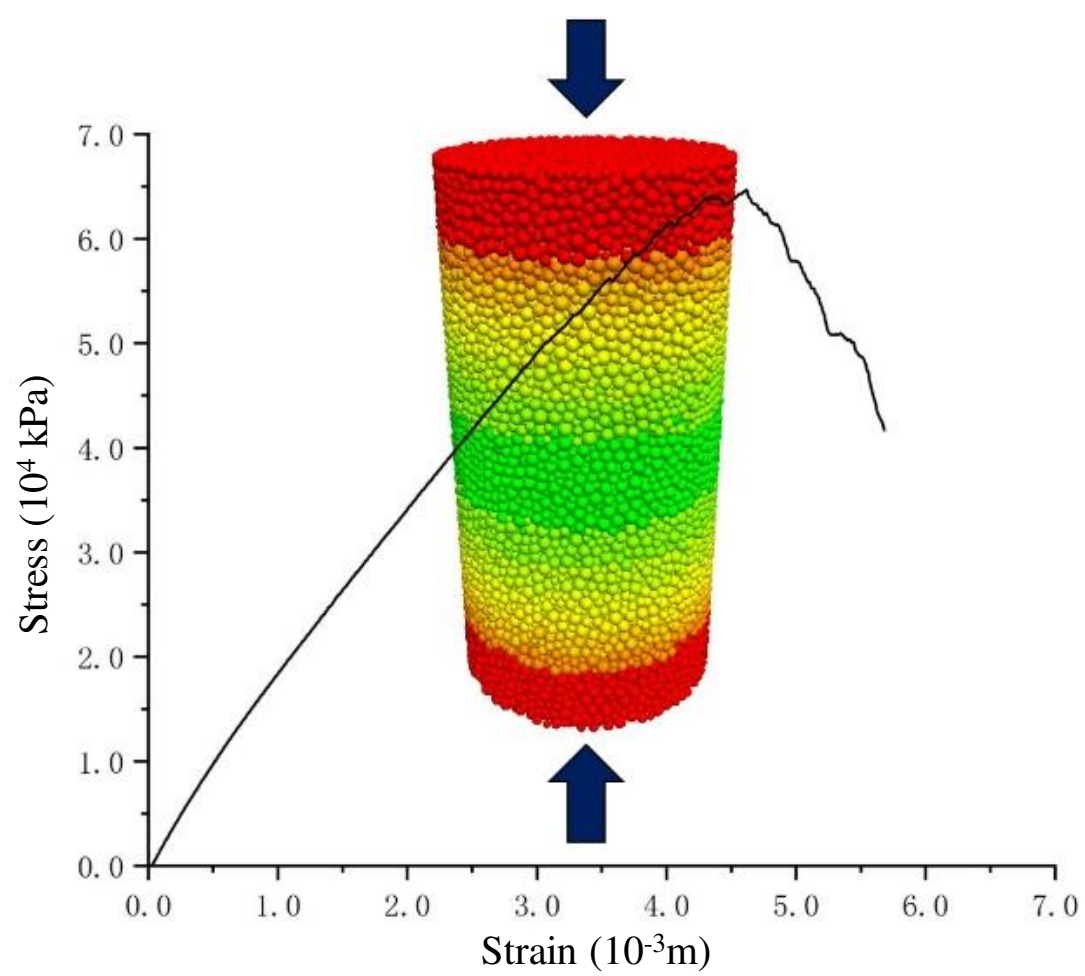

Fig. 6 The simulated triaxial test model 


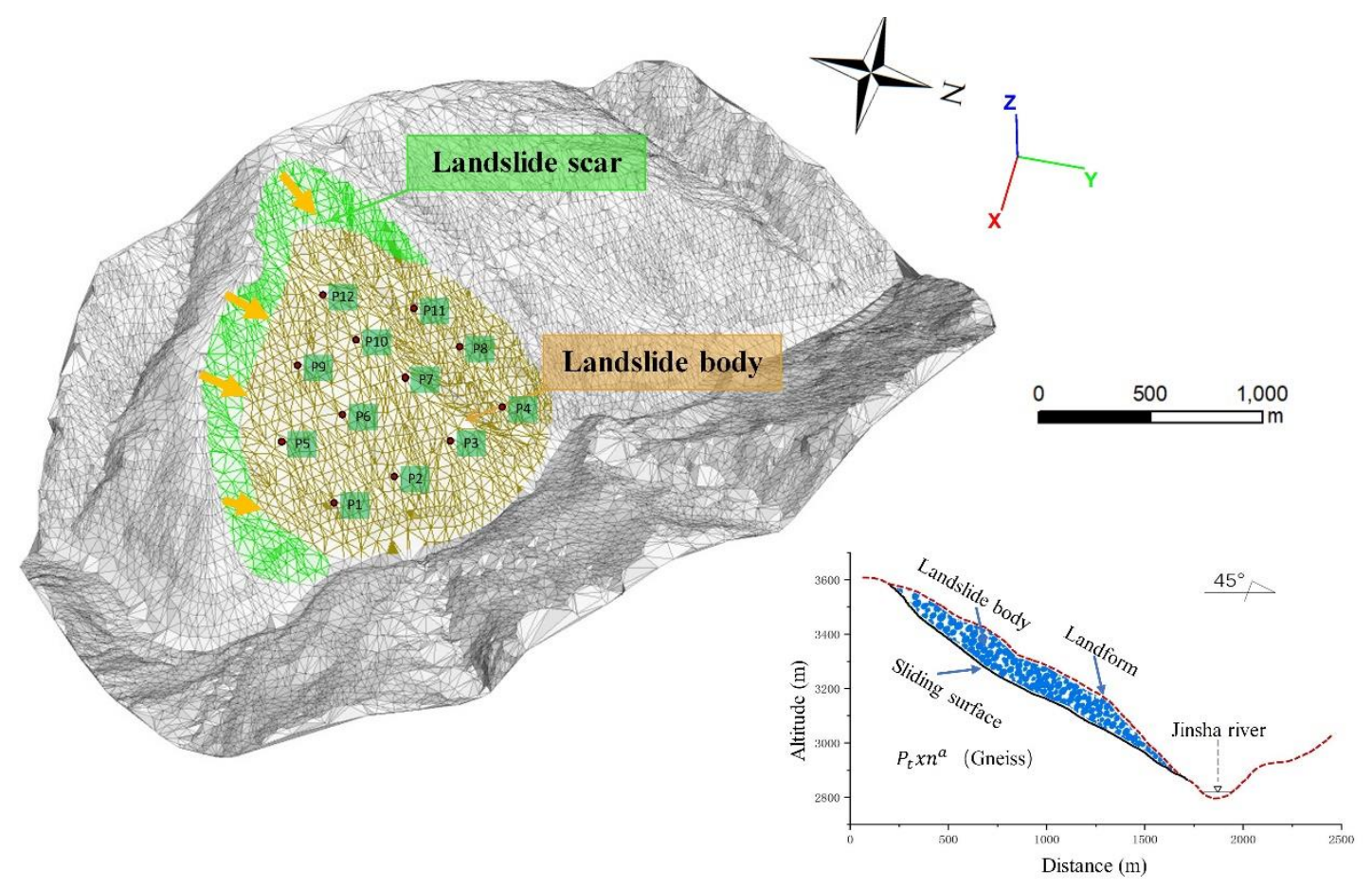

Fig. 7 Simulation model of the Xiaomojiu landslide (base terrain from UAV obtained by authors)

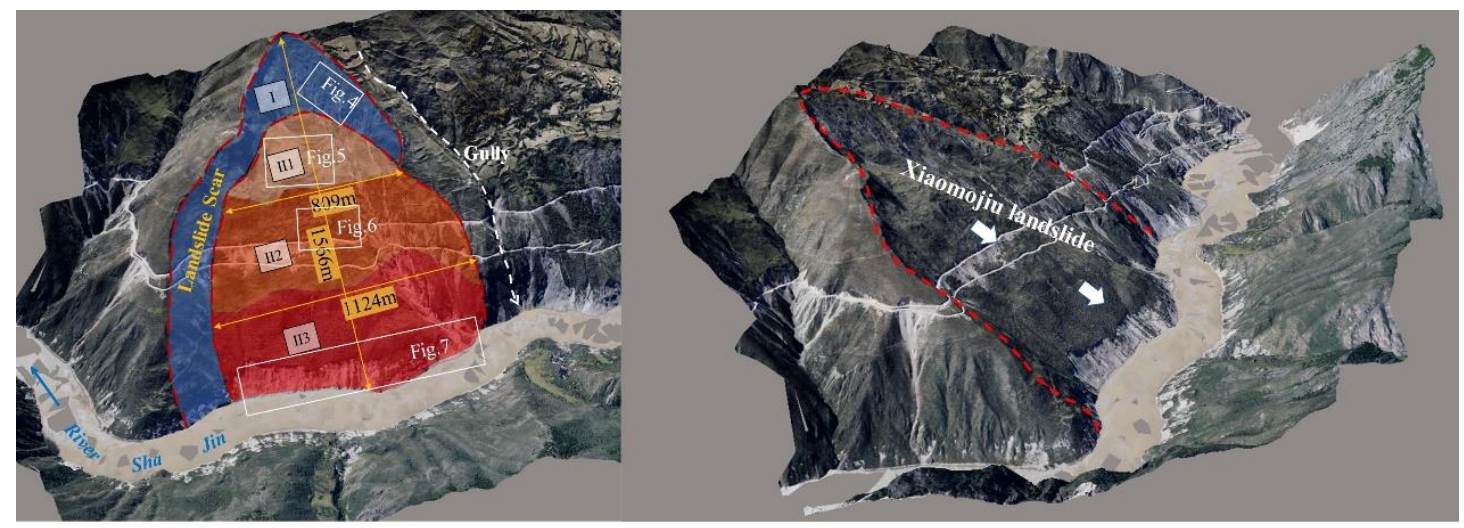

22 Fig. 8 The landslide deformation zone and side view of the landslide (base imagery and terrain from UAV 23 obtained by authors) 


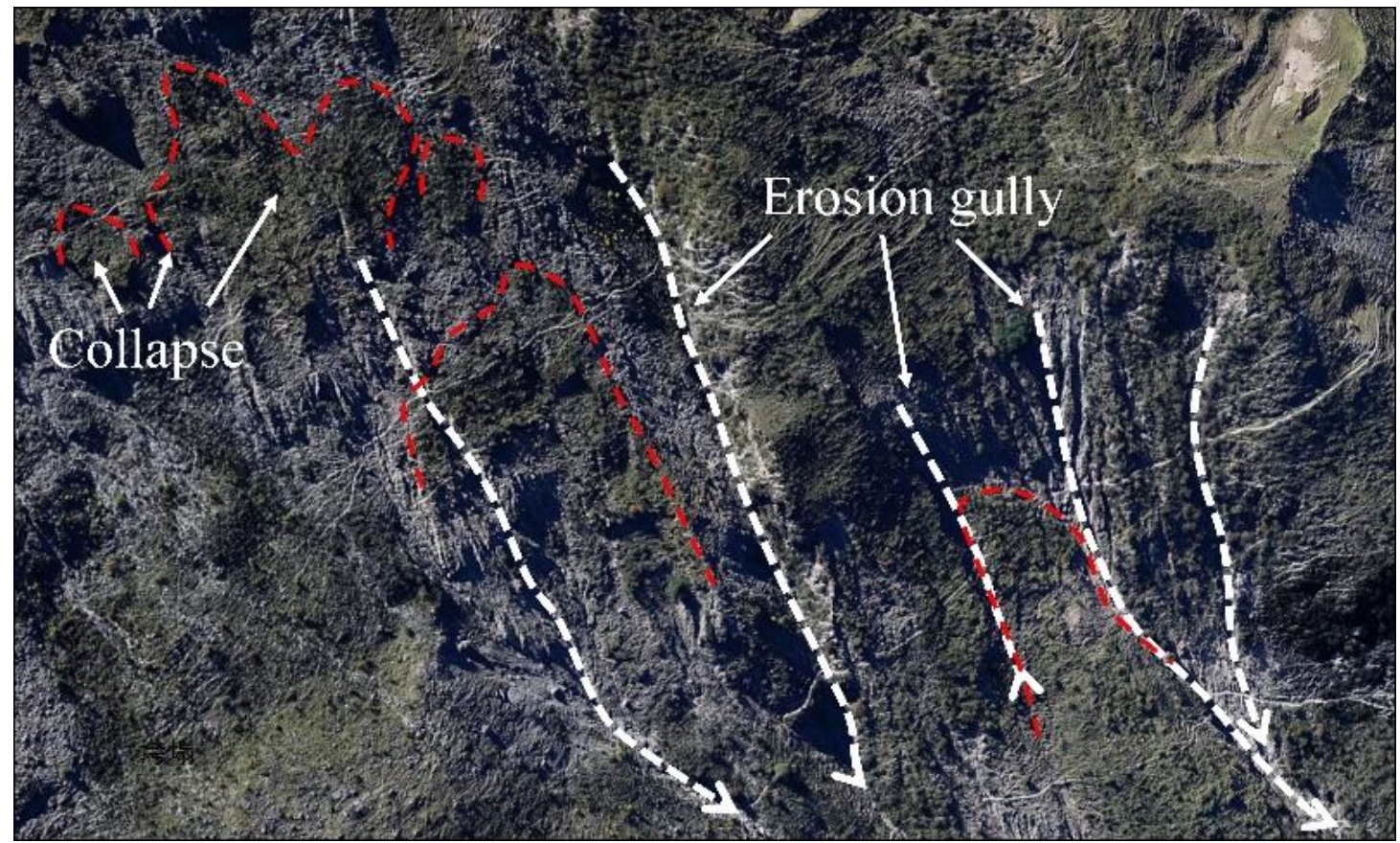

Fig. 9 The landslide scar area (base imagery from UAV obtained by authors)

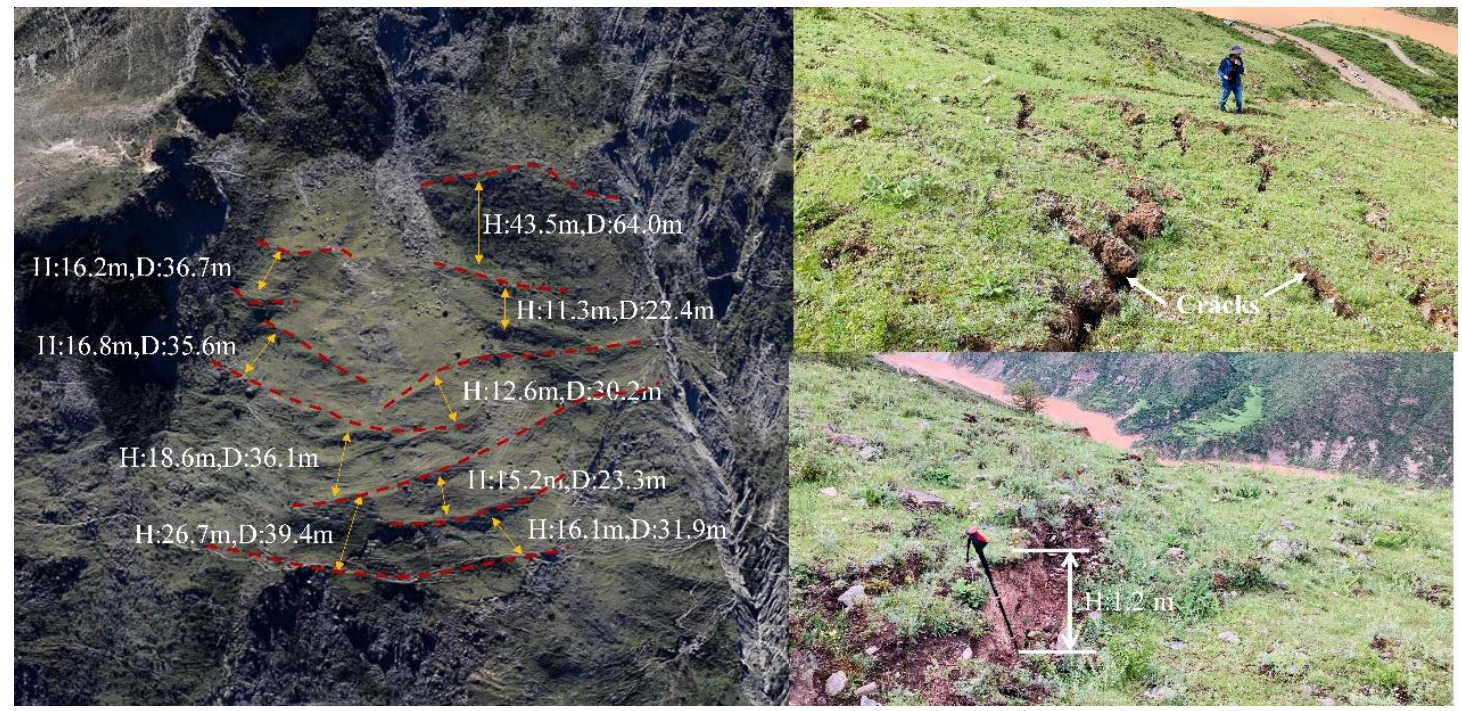

Fig. 10 The upper sliding deformation zone (base imagery from UAV obtained by authors) 


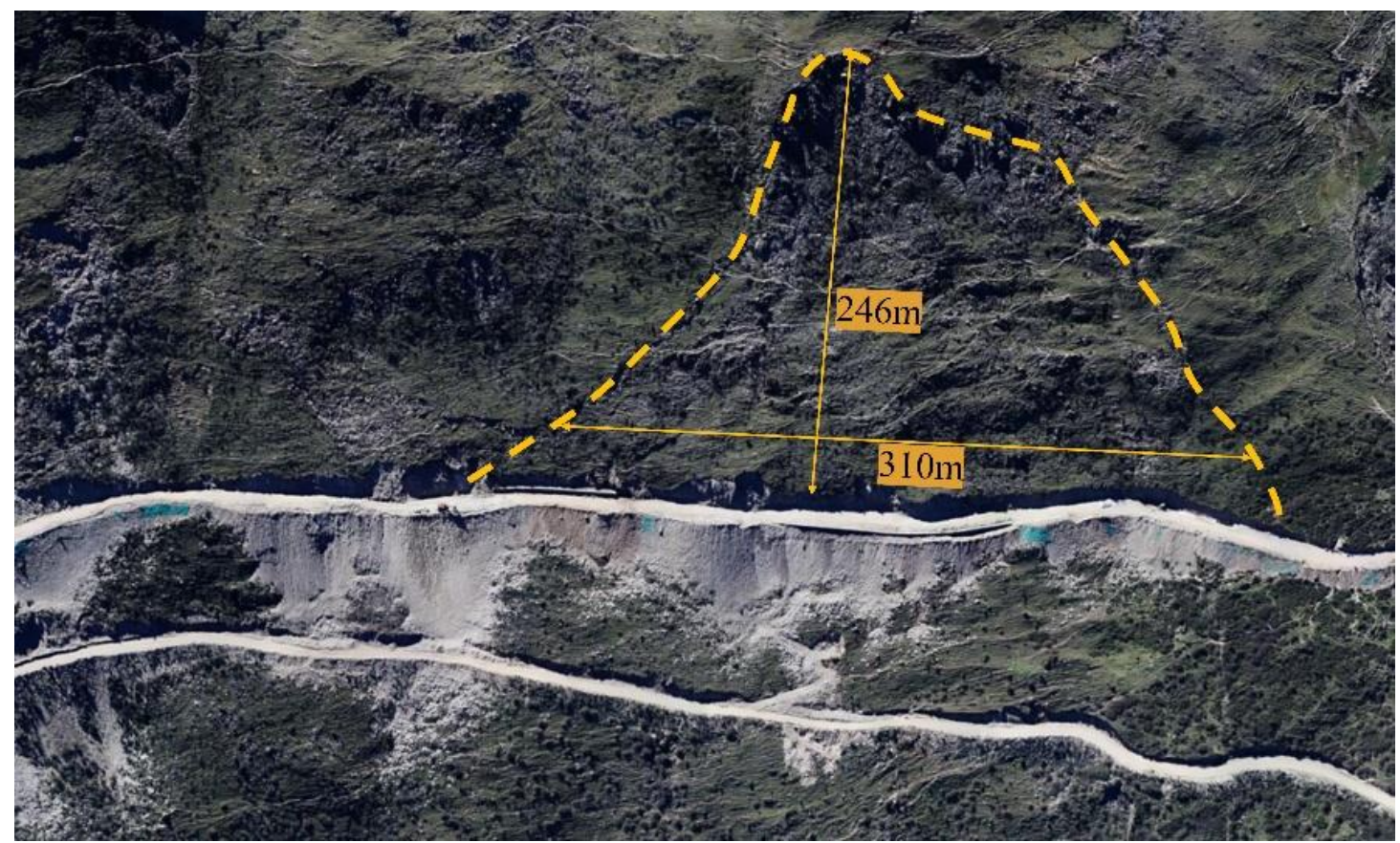

Fig. 11 The middle compression deformation zone (base imagery from UAV obtained by authors)

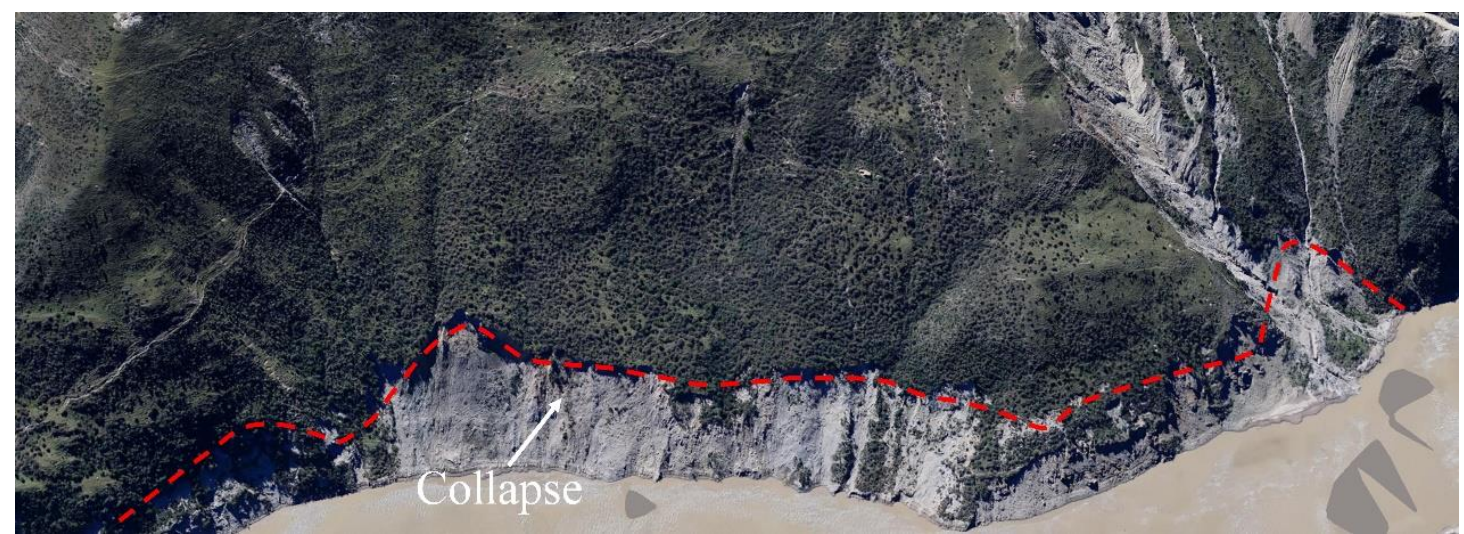

Fig. 12 The slope toe stress concentration zone (base imagery from UAV obtained by authors) 

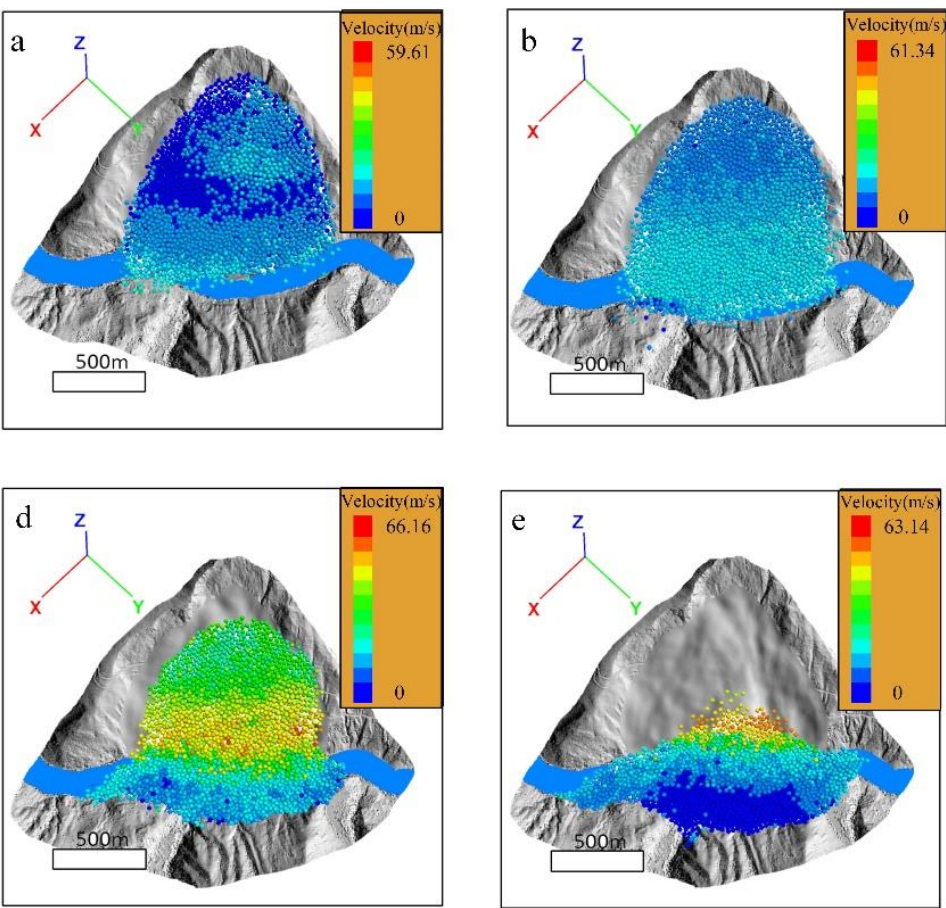
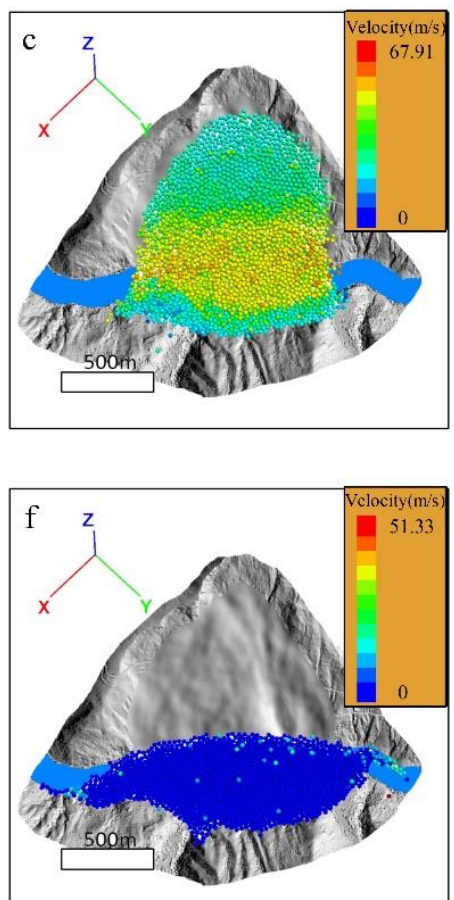

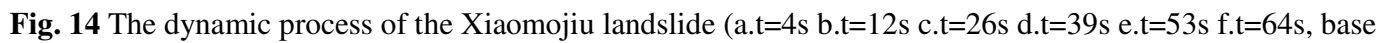
terrain from UAV obtained by authors) 


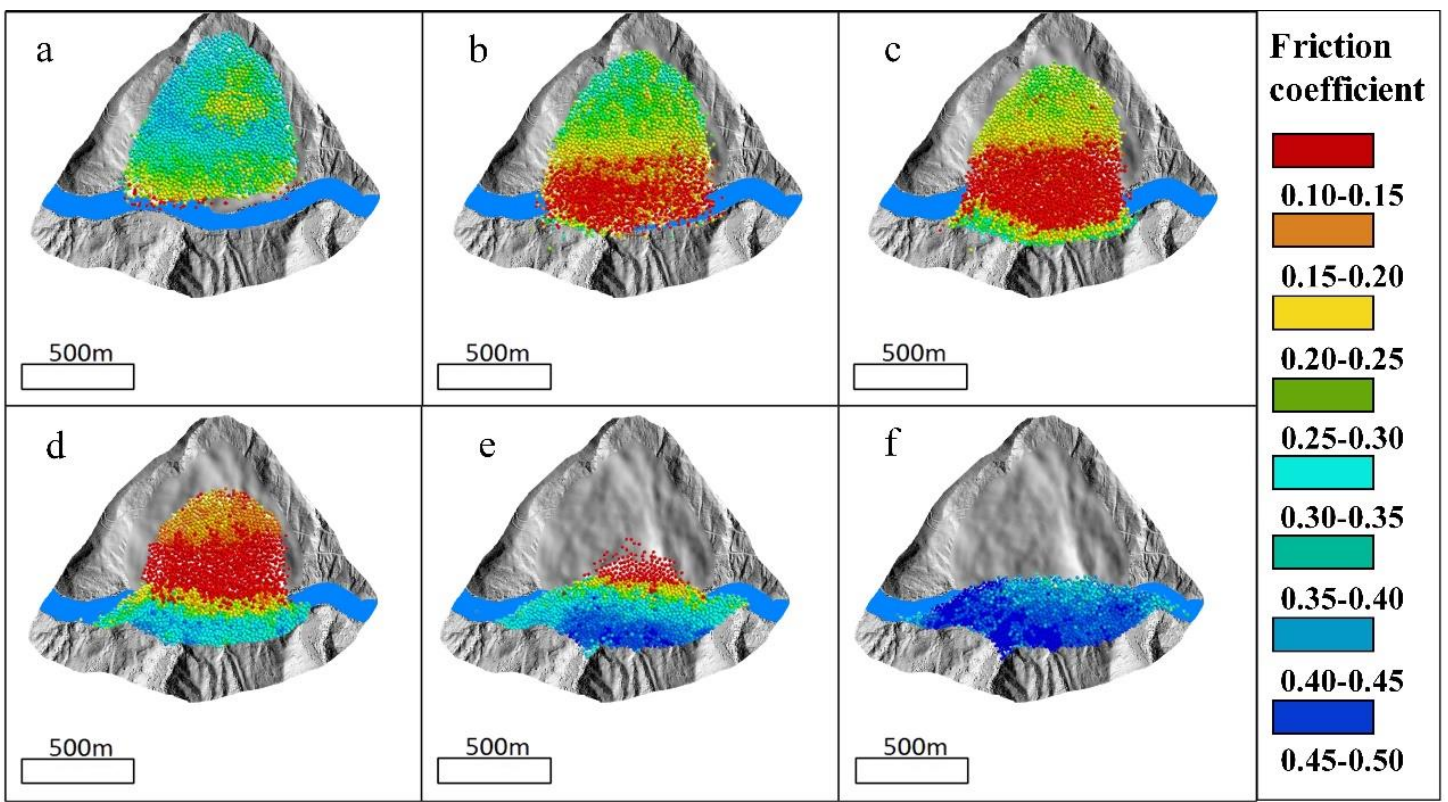

Fig. 15 The changing characteristics of the friction coefficient during dynamic process (a.t=4s b.t=12s c.t=26s d. $t=39 \mathrm{~s}$ e. $\mathrm{t}=53 \mathrm{~s}$ f.t=64s, base terrain from UAV obtained by authors)
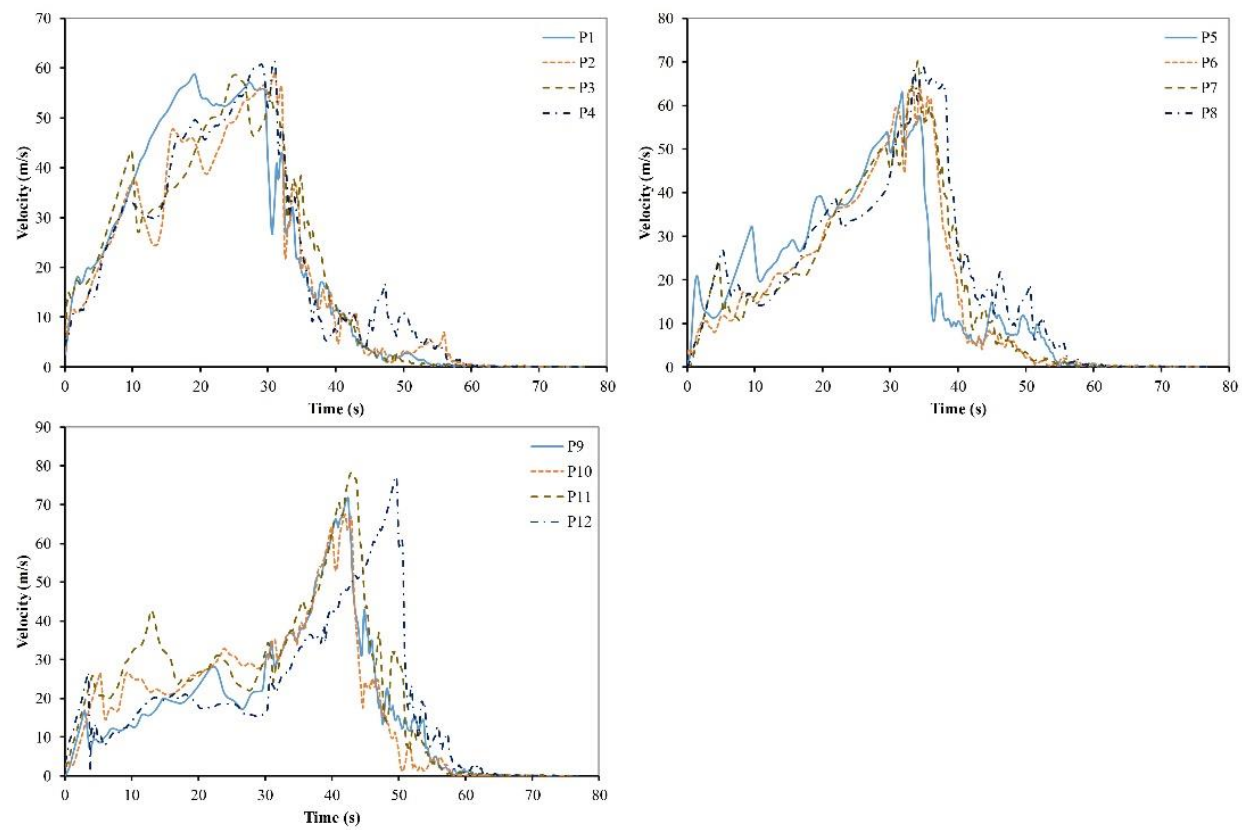

Fig. 16 The point velocity of the Xiaomojiu landslide 

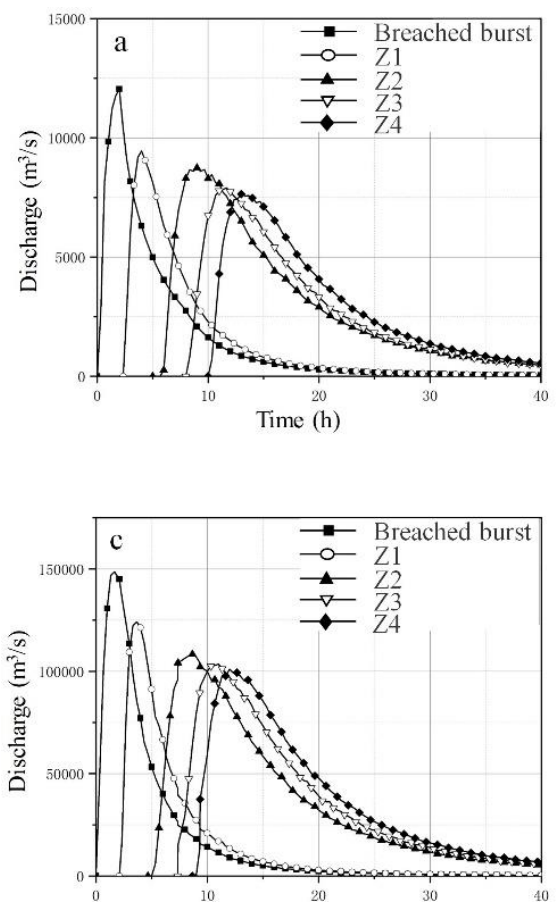
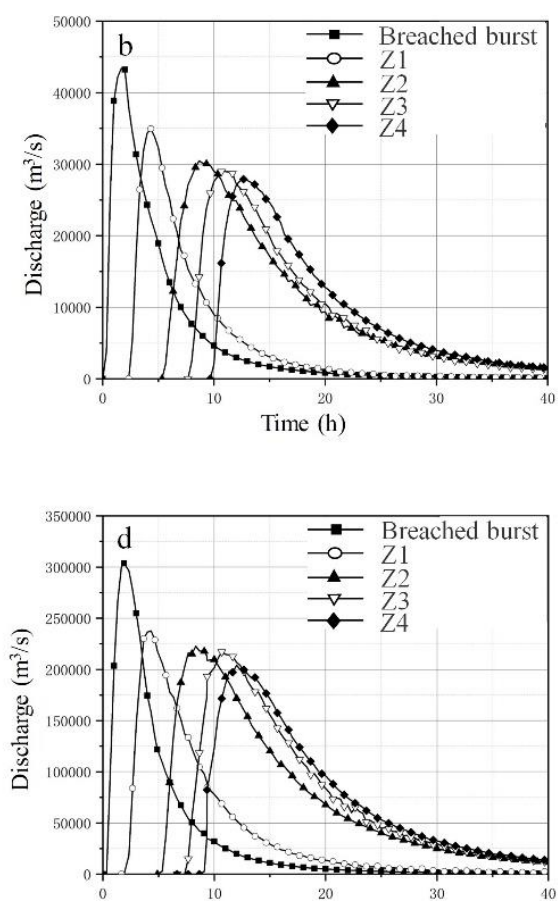

Fig. 18 Flood discharge processes for different dam failures at different sites (a, 15\% dam failure; b, 25\% dam failure; c, 50\% dam failure; $\mathrm{d}, 75 \%$ dam failure) 


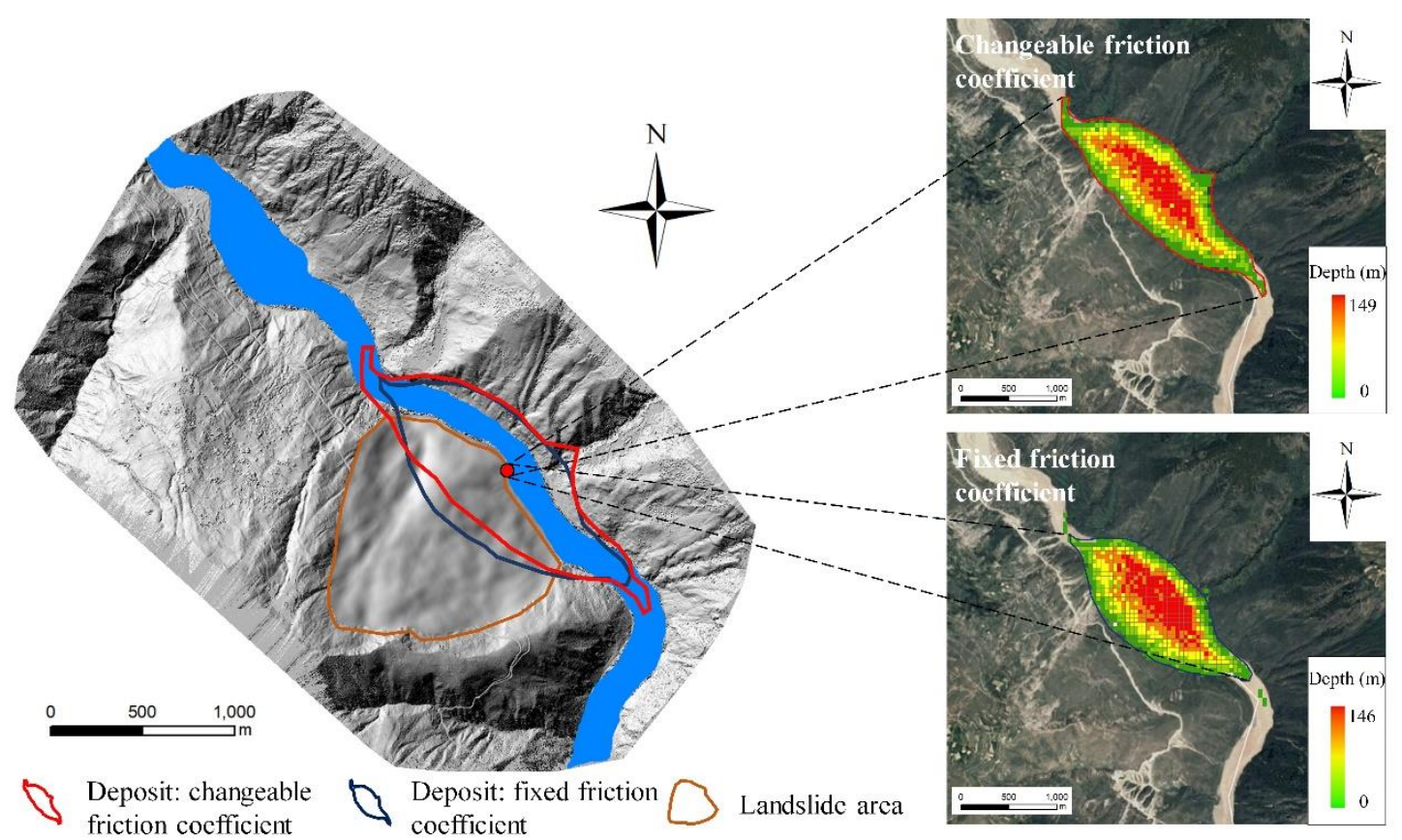

Fig.19 The different deposition characteristics of the Xiaomojiu landslide with changeable and fixed friction coefficients (base imagery and terrain from UAV obtained by authors)

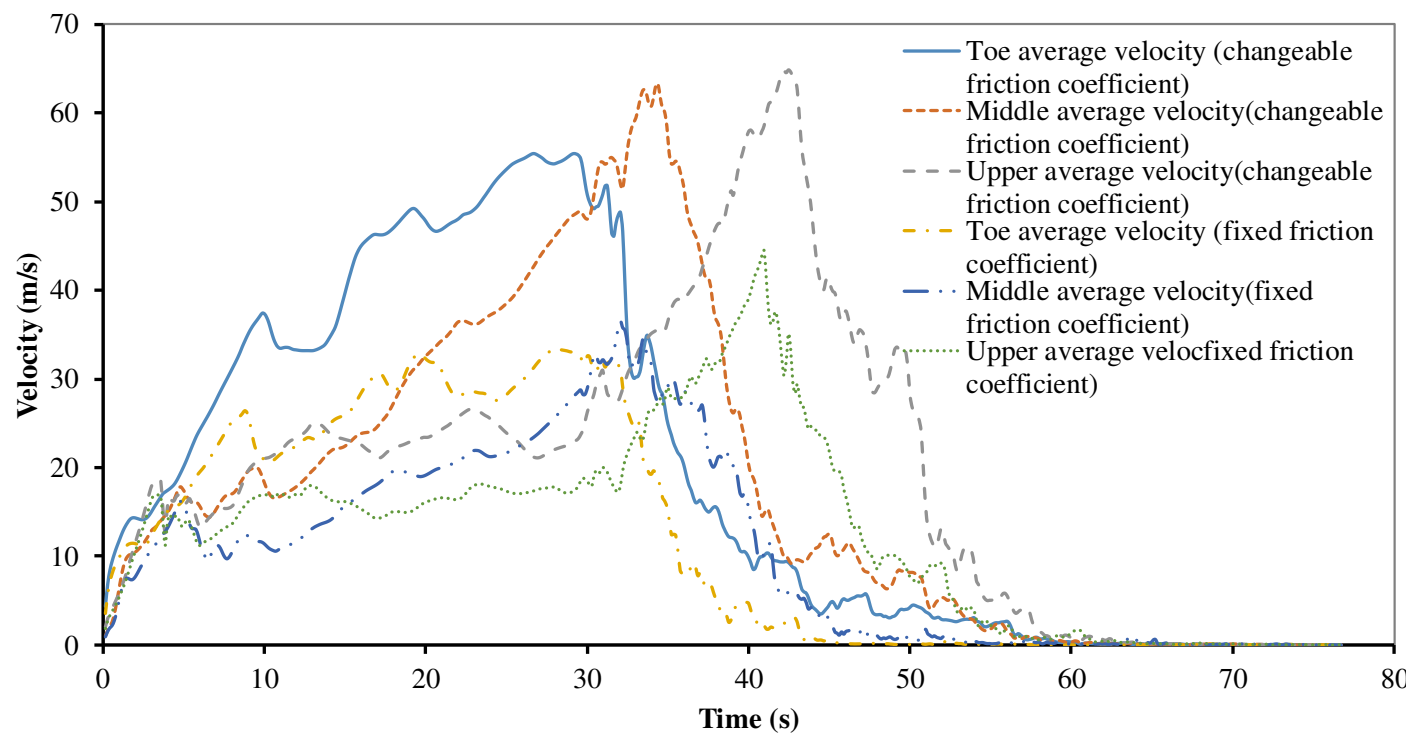

Fig. 20 Average velocities of different parts of the Xiaomojiu landslide with changeable and fixed friction coefficients 